\title{
UNIVERSITÄT HOHENHEIM
}

\author{
HOHENHEIMER \\ DISKUSSIONSBEITRÄGE
}

Downward Nominal Wage Rigidity in Europe:

An Analysis of European Micro

Data from the ECHP

1994-2001

by

Christoph Knoppik and Thomas Beissinger

$$
\text { Nr. 275/2006 }
$$

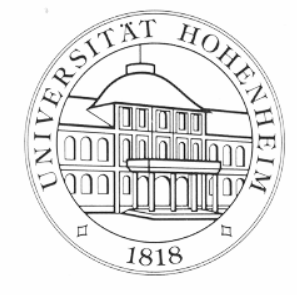

Institut für Volkswirtschaftslehre (520)

Universität Hohenheim, 70593 Stuttgart

ISSN 0930-8334 


\title{
Downward Nominal Wage Rigidity in Europe: An Analysis of European Micro Data from the ECHP
}

\section{4-2001*}

\author{
Christoph Knoppik ${ }^{\dagger}$ \\ University of Bamberg \\ Thomas Beissinger \\ University of Hohenheim and IZA (Bonn)
}

July 2006

\section{Abstract}

This paper substantially extends the limited available evidence on existence and extent of downward nominal wage rigidity in the European Union and the Euro Area. For this purpose we develop an econometric multi-country model based on Kahn's (1997) histogram-location approach and apply it to employee micro data from the European Community Household Panel (ECHP) for twelve of the EU's current member states. Our estimates for the degree of downward nominal wage rigidity on the national as well as the EU-wide level point to marked downward nominal wage rigidity within the European Union.

Keywords: $\quad$ Downward Nominal Wage Rigidity; Wage Stickiness; European Community Household Panel; ECHP; Histogram-Location Approach; European Union; Euro Area. JEL-classification: J30; E24.

* An earlier version of this paper has been circulated as IZA Discussion Paper 1492.

We would like to thank Laszlo Goerke, Harry Haupt, Joachim Möller, Walter Oberhofer, Friedhelm Pfeiffer, and Philippe Van Kerm for valuable suggestions. We have benefited from discussions with seminar participants at the European University Viadrina at Frankfurt/Oder, the University of Hohenheim, the University of Mainz, the University of Regensburg, the University of Bamberg, the ZEW (Mannheim), the Bundesbank, and the IAB (Nürnberg), and with participants of sessions at EPUNET, EEA, and EALE conferences, where earlier stages of this work have been presented. This research was funded in part by a grant of the European Commission under the 'Transnational Access to major Research Infrastructures' contract HPRI-CT-200100128 hosted by IRISS-C/I at CEPS/ INSTEAD Differdange (Luxembourg).

$\dagger$ Prof. Dr. Christoph Knoppik, phone: +49 +951 863 2634, e-mail: christoph.knoppik@sowi.uni-bamberg.de, Feldkirchenstraße 21, D-96045 Bamberg, Germany. 


\section{Introduction}

Whether and to which extent nominal wages are downwardly rigid are widely considered unresolved questions. Their scientific importance derives from their key role for the understanding of the workings of the labor market and from their implications for the shape of the longrun Phillips curve. Their policy relevance is due to the fact that downward nominal wage rigidity (DNWR) may lead to inadvertently high costs of low inflation targets in terms of higher long-term unemployment. Correspondingly, empirical evidence with respect to nominal rigidity is indispensable for an evaluation of recent low inflation targets of monetary policy makers.

At present, only for some European countries such evidence with respect to downward nominal wage rigidity does exist, see the surveys of Kramarz (2001), Stiglbauer (2002), and Rodríguez-Palenzuela, Camba-Mendez and Garcia (2003). In several cases, the evidence is purely descriptive, it seems contradictory, and it is hard to compare across countries, because of differences in methods and data. This state of recent research has led the European Central Bank to conclude that 'the importance in practice of downward nominal rigidities is highly uncertain and the empirical evidence is not conclusive, particularly for the euro area', European Central Bank (2003, p. 14).

This paper addresses this critique by substantially extending the available evidence on existence and extent of downward nominal wage rigidity in the European Union and the Euro Area. The analysis is based on the European Community Household Panel (ECHP), which is a large-scale annual longitudinal survey for the 'old' 15 member states of the European Union comprising the years 1994 to 2001. The great advantage of the ECHP is the uniform questionnaire asked in the EU-countries, which makes the direct comparison of data across countries and over time possible. The comparison of results is also facilitated by use of a uniform method of analysis for the EU and Euro Area as a whole as well as for the individual member countries. For this purpose we develop an econometric multi-country model based on a widespread quantitative method of analysis in this context, the histogram-location approach introduced by Kahn (1997), in order to guarantee a high degree of comparability with earlier results. Further advantages of this line of analysis are that it is easier to interpret and based on fewer functional assumptions than the best alternative, the earnings-function approach proposed by Altonji and Devereux (2000). The most important drawback of the histogramlocation approach, its lack of treatment of measurement problems, is not problematic in the context of a uniform cross-country data source, since measured degrees of downward nominal wage rigidity can consistently be interpreted as lower bounds of true nominal wage rigidity across countries. 
The remainder of the paper is structured as follows. Sections 2 and 3 explain the histogram-location approach and our proposed extensions. Sections 4 and 5 describe in some detail the ECHP data used and present descriptive evidence. Section 6 contains a description of the empirical implementation and the results with respect to existence and extent of downward nominal wage rigidity. The results of robustness checks are presented in Section 7. In Section 8 the estimation results are compared with results from the literature. Finally, in Section 9 we summarize our findings and offer conclusions and a brief outlook.

\section{Histogram-location approach}

The histogram-location approach of Kahn (1997) models annual location-centered distributions of wage changes by histograms and tests in an econometric model of the histograms whether changes in shape of the histograms can be explained as the systematic interplay of downward nominal wage rigidity and changes in location of the original, uncentered distributions. ${ }^{1}$

\subsection{Basic principle}

The histogram-location approach's principle of identification is that of joint variation of location and shape. ${ }^{2}$ It relies on the fact that distributions of wage changes react differently to changes in location of the distribution under the alternative regimes of either nominal wage flexibility or nominal wage rigidity. Under downward nominal wage rigidity there will be systematic joint variation of location and shape, but no such variation in shape occurs under nominal wage flexibility.

This fundamental difference between regimes is illustrated in the upper left quarter of Figure 1 in columns (1) and (2), rows a) and b). Column (1) shows how the distribution of wage changes reacts to changes in the underlying determinants of average wage growth, e.g. changes of the rate of inflation, under a regime of nominal wage flexibility: the location (e.g. the median), indicated in the graphs by $l$, shifts, but the overall shape of the distribution remains unchanged between (1a) and (1b). This distribution under wage flexibility is also referred to as notional, hypothetical or counterfactual distribution. The distribution under downward nominal wage rigidity deviates from the counterfactual distribution. Panel (2a) illustrates the effects of nominal rigidity on the shape of the distribution for a given location. The left tail is thinner than under nominal wage flexibility (thinning effect), reflecting that a number of intended nominal wage reductions cannot take place because of rigidity. At the same time the bin that contains the zero nominal wage change is larger than under flexibility,

1 The term 'wage' is used for any type of earnings from labor. The earnings variables used are discussed in Section 4.

2 A number of expositions of the histogram-location approach are available in the literature, e.g. Beissinger and Knoppik (2001), Stiglbauer (2002), Knoppik and Dittmar (2002), Lebow, Saks and Wilson (2003). 
since it contains the wage freezes that occur instead of the nominal wage cuts (pile-up effect). The reaction to shifts of the distribution also differs from the case of nominal wage flexibility. The shape of the distribution in panel (2b) has changed and is more similar to the counterfactual distribution than that in panel (2a) since due to the shift of location to the right a smaller part of the left tail is affected by thinning and the pile up of the zero bin is correspondingly smaller.

\section{Figure 1}

The histogram-location approach makes use of the "principle of joint variation of location and shape' by quantifying the changes in shape in empirical histograms of wage changes. In order to make corresponding parts of the distribution better comparable, the situation under downward nominal wage rigidity is now presented with location-centered histograms of $\Delta w^{c}=\Delta w-l$ in column (3), row a) and b). For ease of reference, the relevant histogram bins are numbered from right to left, starting with one for the bin just left of $\Delta w^{c}=0$ as in column (3) of Figure 1. $\Delta w^{c}=0-l$ corresponds to the zero nominal wage change; the different locations of $-l$ on the $x$-axes point to the underlying differences in location of the two uncentered distributions. The differences in shape can be better distinguished in this graphical representation since the distributions and the bins representing corresponding parts of the distribution are now vertically aligned. Bin 1 is of identical size in both panels, since it contains positive nominal wage changes (i.e. it is a 'positive bin', on the right of the respective $\Delta w^{c}=0-l$ ) in both scenarios of low or high location (high inflation) and is therefore unaffected by nominal rigidity. Bins 2 to 4, however, differ between panels (3a) and (3b). Bin 2, in the low location (low inflation) scenario, is the 'zero bin' containing the pile up ( $\Delta w^{c}=0-l$ falls into it), whereas in the high location (high inflation) scenario bin 2 still contains only positive nominal changes, unaffected by downward nominal wage rigidity. Going from right to left, bin 3 is still a positive bin in the high location (high inflation) scenario, but is, in the low location (low inflation) scenario, a 'negative bin' containing only negative nominal wage changes. Yet a little further left, it is bin 4 that is the zero bin in the high location (high inflation) scenario, but has again negative bin status under the low location (low inflation) scenario. The remaining bins, starting with bin 5, are of identical size in both panels, i.e. reduced by thinning, since these are negative bins (left of the respective $\Delta w^{c}=0-l$ ) containing only negative nominal wage changes in both scenarios. The systematic differences in the size of the bins clearly point to the presence of downward nominal wage rigidity built into the numerical example underlying the graphs: relative to their size as positive bins, bins of the same number are smaller when they are negative bins and larger when they are zero bins. In the histogram-location approach these systematic joint changes of shape and location are captured in a formal econometric model, if they do exist. 
The lower part of Figure 1, comprising rows c) and d), serves to illustrate two potential problems for the analysis, narrow distributions and little variation of location, by introducing a second country B differing from the first country A. As one obvious difference, Country B's distributions are narrower. As a consequence, the effect of downward nominal wage rigidity in panel (2c) looks much weaker than that in panel (2a) of the first country, although the percentage of desired wage cuts that are prevented by rigidity and the location of the distribution are the same by construction of the numerical example underlying the visualization. A second difference is the smaller variation in location (inflation) from low to moderate for country B, in contrast to variation from low to high for country A. This leads to less observed variation in bin sizes in panels (3c) and (3d) and thereby to a potential identification problem. Such a lack of observed distributions with different locations would make the combination of evidence from more than one country particularly desirable. However, as column 3 of Figure 1 vividly illustrates, observed histograms from the two countries must not be combined, because at this point it is unclear how the effects of downward nominal wage rigidity on bin sizes could be disentangled from differences in bin sizes that simply stem from different wage change distributions in the two countries. We will return to this problem and ways to overcome it in Section 3.

\subsection{Basic econometric model}

The basic econometric model of the histogram-location approach explains the observed relative frequency $P_{r t}$ of wage changes in bin $r$ in period $t$ of the histogram of location-centered per cent annual wage changes. The bin size $P_{r t}$ is equal to the product of bin width $b$ and height $h, P_{r t}=b h$. Bin $r$ represents per cent nominal wage changes that are between $r$ and $r-1$ times the bin width $b$ smaller than the rate of wage change at the location of the uncentered distribution. The explanatory variables are dummy variables that capture bin status in different bins and years, i.e. whether the bins contain negative, zero, or positive nominal wage changes. The unknown parameters that are to be estimated are the rigidity parameter $\rho$, the counterfactual bin sizes $\alpha_{r}$ that would prevail under wage flexibility, and the pile-up parameter $\gamma$. The model consists of the following system of equations:

$$
P_{r t}=\alpha_{r} \underbrace{\left(1-\rho D N_{r t}\right)}_{\text {thinning }}+\underbrace{\left(\gamma+\rho \sum_{j=r_{\min }}^{r_{\max }} \alpha_{j} D N_{j t}\right) D Z_{r t}}_{\text {pile-up }}+\mu_{r t} \text { for } r=r_{\min } \ldots r_{\max } .
$$

Bins' status as a negative bin, zero bin or positive bin is encoded in two dummy variables, $D N_{r t}$ and $D Z_{r t}$. A value of one in $D N_{r t}$ indicates the exclusive presence of negative nominal wage changes in the bin, whereas a value of one in $D Z_{r t}$ indicates the presence of zero nominal wage changes in that bin. Bins with only positive changes are coded by setting to zero both $D N_{r t}$ and $D Z_{r t}$. The rigidity parameter $\rho$ can directly be interpreted as the degree of downward nominal wage rigidity, since it is equal to the proportion of nominal notional wage 
cuts that are prevented by the existence of downward nominal wage rigidity. The counterfactual bin sizes $\alpha_{r}$ are constant parameters because of the assumption of a time-invariant counterfactual distribution (up to shifts in location). ${ }^{3}$

System (1) is a partial model of the total histogram including $R=r_{\max }-r_{\min }+1$ equations, one for each bin modeled; this assumption will later be relaxed. All bins that change status at least once during the sample period contribute to the identification of downward nominal wage rigidity and should be included in the model. $r_{\min }$ should therefore be the bin with the smallest number that changes from positive to zero status at least once in the sample period, or a bin with an even lower number, and analogously for $r_{\max }$. Note that the estimation of the system is based on $N=R \cdot T$ observed bin sizes, given $T$ observed histograms. Each equation of system (1) covers the three cases of negative, zero, or positive bins. Positive bins $\left(D N_{r t}=0\right.$ and $\left.D Z_{r t}=0\right)$ are explained by the counterfactual bin sizes $\alpha_{r}$. In the case of negative bins $\left(D N_{r t}=1\right.$ and $\left.D Z_{r t}=0\right)$, a proportion $\rho$ of the counterfactual bin size is subtracted from $\alpha_{r}$. In contrast, for zero bins $\left(D N_{r t}=0\right.$ and $\left.D Z_{r t}=1\right)$ there is a pile-up in addition to the counterfactual bin size from the wage freezes in the negative bins of the same period; parameter $\gamma$ captures the contribution of those negative bins that are too far left to be explicitly modeled, or caused by reasons other than downward nominal wage rigidity.

\subsection{Remarks}

A number of remarks complete the introduction of the basic model. First, the model presented is a simplified version of the "proportional" model or "model 3" in Kahn (1997). The proportional model of downward nominal wage rigidity with uniform degree of rigidity for nominal wage reductions of all sizes is used, because it results in a single measure of rigidity that it easy to interpret and easy to compare to other results in the literature. There is also explicit support for this proportional form of rigidity in Knoppik (2003), an analysis of functional form of downward nominal wage rigidity. Second, note that even this basic specification implies nonlinear cross-equation parameter constraints and requires corresponding estimation procedures. Third, the measure of location must not itself be affected by downward nominal wage rigidity, since this measure captures the shifts of the counterfactual distribution, which through the principle of joint variation of location and shape is crucial for identification in the histogram-location approach. Fourth, Knoppik and Beissinger (2003) showed that measurement error with classical properties tends to hide some of the rigidity present in the data. The estimated degree of downward nominal wage rigidity in the histogram-location approach can therefore be interpreted as a lower bound of the true extent of rigidity.

3 A detailed account of the assumptions underlying this and other approaches to the analysis of downward nominal wage rigidity can be found in Beissinger and Knoppik (2001). 


\section{Extensions of the histogram-location approach for cross-country analysis}

A number of variants of the basic proportional model of the histogram-location approach have been proposed in Kahn (1997), Beissinger and Knoppik (2001), Christofides and Leung (2003), and Castellanos, García-Verdú and Kaplan (2004), but none of these is suitable for cross-country, cross-sectional, or cross-regional analysis with a necessity to deal with potential differences in dispersion as illustrated above.

\subsection{Cross-country options}

In our view there are three different ways in which the histogram-location approach can be used in a cross-country context. The first option is to build isolated national models, i.e. to construct national histogram bin sizes and to estimate national models independently of each other, using the basic econometric model (1) for example. The main drawback of this option for our purposes is that for several countries the distribution of per cent wage changes does exhibit only very little variation in location over the sample period which tends to make estimation less reliable or even impossible.

The second option is to construct one aggregate annual histogram for all countries together and to estimate an aggregate model. However, different developments over time of the location of the underlying national distributions of per cent wage changes give rise to a timevarying mixture of distributions which violates the assumption of time-invariance of the counterfactual distribution.

The third option is to pool the information on national histogram bin sizes and to estimate pooled models. In pooled models, the limited variation in location of the distributions of per cent nominal wage changes is substituted to some degree by cross-country variation in location. Two versions of pooled models, either with uniform or country-specific degrees of downward nominal wage rigidity are considered in the remainder of this section.

\subsection{Pooled model}

The pooled model with uniform parameters essentially consists of a version of equation (1) that is additionally indexed with a country index $c$

$$
P_{r c t}=\alpha_{r} \underbrace{\left(1-\rho D N_{r c t}\right)}_{\text {thinning }}+\underbrace{\left(\gamma+\rho \sum_{j=r_{\min }}^{r_{\max }} \alpha_{j} D N_{j c t}\right) D Z_{r c t}}_{\text {pile }-u p}+\mu_{r c t} \text { for } r=r_{\min } \ldots r_{\max } \text {. }
$$


Stacked data on bin sizes and status dummies from the different countries is used in this case. Note that the estimation of the pooled model is based on $N=R \cdot \sum_{c} T_{c}$ observed bin sizes, where $T_{c}$ is the number of observed histograms of country $c$. The pooled model with national rigidity and pile-up parameters is given by the system of equations (3).

$$
P_{r c t}=\alpha_{r} \underbrace{\left(1-\left(\sum_{i} \rho_{i} D C_{r c t}^{i}\right) D N_{r c t}\right)}_{\text {thinning }}+\underbrace{\left(\sum_{i} \gamma_{i} D C_{r c t}^{i}+\left(\sum_{i} \rho_{i} D C_{r c t}^{i}\right)_{j=r_{\min }}^{r_{\max }} \alpha_{j} D N_{j c t}\right) D Z_{r c t}}_{\text {pile-up }}+\mu_{r c t}
$$

$$
\text { for } r=r_{\min } \ldots r_{\max } \text {. }
$$

Country dummies $D C_{r c t}^{i}$ for each country $i$ are used in replacing the uniform rigidity and pile-up parameter in equation (2). Specifically, $\sum_{i} \rho_{i} D C_{r c t}^{i}$ is used to replace $\rho$, and $\sum_{i} \gamma_{i} D C_{r c t}^{i}$ replaces $\gamma$, where summation runs over all countries covered. The assumption of invariance of the counterfactual distribution is extended in the pooled model to hold over countries as well as over time which is reflected in the country-independent counterfactual bin sizes $\alpha_{r}$. Any potential country differences of the counterfactual therefore have to be eliminated. Centering the national histograms takes account of the national differences in location. Additional differences in dispersion can be taken into account by standardizing the distributions.

\subsection{Standardization}

As discussed in Section 2.1, Figure 1 illustrates wage change distributions of two countries that differ in their dispersion. The location-centered histograms of column 3 in Figure 1 make it clear that because of these differences histograms from countries A and B must not be used in a joint analysis, unless the analysis corrects for the differences in dispersion. The means for correction are histograms of standardized wage changes, where the standardized per cent wage changes $\Delta w^{s}$ are defined by

$$
\Delta w^{s}=\frac{\Delta w-l}{v}
$$

with location parameter $l$ and dispersion parameter $v$. Under standardization, zero bin status is determined by whether (in a given period) the bin contains the standardized wage change that corresponds to the original zero nominal wage change, $\Delta w^{s}=(0-l) / v$. Column 4 of Figure 1 illustrates that, after standardization, those parts of the distribution from both countries that are not affected by downward nominal wage rigidity are identical. This is true, for example, of bin 1, a positive bin in all periods in both countries. Conversely, remaining deviations of a bin's size from its size as a positive bin, whether they occur across periods or across countries, can now be interpreted as signs of downward nominal wage rigidity. Standardization effectively relaxes the assumption of time-invariant counterfactual distribution (up to 
variation in location) and replaces it by the weaker assumption of time-invariant counterfactual distribution (up to variation in location and some parameter of dispersion).

The choice of a suitable measure of variability depends on the question to be addressed. In the context of their otherwise unrelated analysis of downward nominal wage rigidity in aggregate industry wage data, Holden and Wulfsberg (2004) are interested in unbiased type I errors in a test of the null hypothesis of wage flexibility. For their analysis it therefore does not matter whether the measure of variability $v$ is affected by downward nominal wage rigidity or not, and they choose the interquartile range as their preferred measure of variability, i.e. $v^{7525}=q_{75}-q_{25}$, where $q_{75}$ and $q_{25}$ denote the third and first quartile $\left(75^{\text {th }}\right.$ and $25^{\text {th }}$ percentile). Since we are interested in estimates of the extent of downward nominal wage rigidity, the measure of variability must not be affected by downward nominal wage rigidity. We therefore propose the use of interpercentile ranges between the measure of location (which again must not be affected by downward nominal wage rigidity) and some higher percentile. For example, if the $60^{\text {th }}$ percentile is used for location, $l=q_{60}$, the upper percentile could be $q_{80}$ leading to

$$
v^{80 \mid 60}=q_{80}-q_{60},
$$

and a corresponding standardization of

$$
\Delta w^{s}=\frac{\Delta w-q_{60}}{v^{80 \mid 60}}=\frac{\Delta w-q_{60}}{q_{80}-q_{60}} .
$$

\subsection{Closed model}

A problem of the basic model is that it is a partial model and may thereby lead to inconsistent results. The solution is to 'close' the model by modeling the full left tail of the histogram. In the basic model (1) the part of the distribution to the left of $r_{\max }$ is only taken into account implicitly, by adding the ad hoc "additional pile-up" parameter $\gamma$. The construction of location-centered histograms implies that the counterfactual outer left tail has probability mass of $F(q)-\sum_{j=1}^{r_{\max }} \alpha_{j}$, i.e. is equal to the difference between the percentile used as measure of location and the sum of all counterfactual bin sizes up to $r_{\max }$. Therefore, because of the proportional functional form of downward nominal wage rigidity assumed in the model, the pile-up from the far left must equal $\rho$ times this difference. This restriction, $\gamma=\rho\left(F(q)-\sum_{j=1}^{r_{\max }} \alpha_{j}\right)$, however, is not taken into account in the partial model and may therefore be violated in estimates obtained from the basic model. In order to close the model, the restriction can be used to replace the pile-up parameter $\gamma$ in systems (1), (2), or (3). 
For example, system (1) then becomes:

$$
P_{r t}=\alpha_{r} \underbrace{\left(1-\rho D N_{r t}\right)}_{\text {thinning }}+\underbrace{\left(\rho\left(F(q)-\sum_{j=1}^{r_{\max }} \alpha_{j}\right)+\rho \sum_{j=1}^{r_{\max }} \alpha_{j} D N_{j t}\right) D Z_{r t}}_{\text {pile-up }}+\mu_{r t} \text { for } r=1 \ldots r_{\max } .
$$

Note that no explicit equation for the probability mass to the left of $r_{\max }$ is needed since it is implied by the other bin sizes. Such an equation is not admissible either, because of the dependence of the error terms over the closed model. ${ }^{4}$ Note also that $r_{\min }$ has to be set to one.

\section{Data and definition of the reference subsample}

The analysis is based on the European Community Household Panel (ECHP) which is a largescale annual longitudinal survey providing household and personal information on income and socio-economic characteristics for the 15 'old' member states of the European Union (EU). ${ }^{5}$ The ECHP has been centrally designed and coordinated by the Statistical Office of the European Union (Eurostat). The great advantage of the ECHP is the uniform questionnaire asked in the EU-countries which makes the direct comparison of data across countries and over time possible.

The ECHP started in 1994 and ended in 2001, thereby comprising eight waves, the last of which has been made available for scientific use in January 2004. In the first wave in 1994 a sample of about 60,000 nationally representative households with approximately 130,000 individuals aged 16 years and over were interviewed in the then 12 participating Member States. Austria, Finland and Sweden joined the ECHP-project in 1995, 1996 and 1997, respectively. However, the Swedish data cannot be used in the analysis since it only contains crosssectional information. Luxembourg and the Netherlands also have to be excluded because necessary information for the analysis is missing. ${ }^{6}$

For the data selection decisions are made with respect to three broad categories (see Table 1). Later on we will change the sample selection by varying the entries in each category in order to check the robustness of the estimation results. In this section, however, only the specification of our reference subsample is presented. Category a) in Table 1 specifies the type of employees we are considering in the analysis. In line with previous analyses in this field we are interested in 'job stayers', i.e. employees who have a 'stable employment rela-

4 This situation is well known in the context of the estimation of expenditure shares, see e.g. Greene (2003).

5 EPUNet (2004) is a short introduction to the ECHP and a reference to more detailed information; see also Eurostat (2003). A large number of documents on the ECHP is provided by Eurostat (2004). Peracchi (2002) gives a detailed description of the first three waves of the ECHP data.

6 Data for Luxembourg do not contain information on the month of the interview. Moreover, information on the year of start of the current job is missing in most cases. Data for the Netherlands do not contain information on the monthly activity calendar. 
tionship' with an employer for a certain period of time. Job stayers are defined as full-time working employees who do not change the job between two consecutive interviews. For our reference subsample, we additionally require that interviews are at least 8 and at most 16 months apart. We checked the monthly activity calendar provided by the ECHP in order to ensure that the respective person has been in paid employment in each month between interviews. We also excluded all employees from the reference subsample who were more than three days absent from work due to illness or other reasons in the last four weeks preceding the interview.

\section{Table 1}

Category b) of the data selection deals with the socio-economic characteristics of job stayers and the mode of interview. In the reference subsample we consider male employees who are between 21 and 65 years old and are working in industry or services on the basis of a permanent employment contract.

Category c) deals with the type of earnings used in the analysis. The ECHP dataset provides information on monthly and annual nominal earnings from work, i.e. 'current monthly (net and gross) wage and salary earnings' and 'total regular net wage and salary earnings' (referring to the year prior to the wave year). Since the job stayer concept applied in the paper refers to the spell between interviews and not to the calendar year, we use the information on current monthly earnings. ${ }^{7}$ The question whether gross or net earnings are better suited for the analysis is debatable, because arguments for and against each measure can be put forward. For example, the take-home pay may be better known to individuals, but net earnings changes may be affected by changes in the tax system. We decided to use monthly net earnings in the reference subsample, but later it is checked whether the use of gross earnings changes the estimation results. As a further dimension of the earnings measure we also take into account whether reported working hours changed from one interview to the next, or not. In our reference subsample we only considered those job stayers whose working hours remained unchanged in comparison to the preceding interview. ${ }^{8}$ Table 2 contains the number of observations by wave and country, which sum to a total of 70,239 observations for 12 EU countries.

Table 2

7 We also constructed 'calendar year stayers' from the ECHP for whom the annual earnings information is relevant. However, information on working hours or absence from work refers to the actual situation at the time of the interview. Since we want to control for variation in earnings due to variation in working hours and do not want to loose the final wave throughout the analysis, we prefer to work with 'interview stayers'.

8 Details on the variables used for data selection can be found in Appendix A of the Discussion Paper version of this paper, Knoppik and Beissinger (2005). 


\section{Descriptive evidence}

In this section descriptive evidence for the existence of downward nominal wage rigidity is presented. Figure 2 plots the distributions of per cent changes of monthly net earnings between two consecutive interview dates for each country based on the reference subsample defined in the preceding section. This figure provides some preliminary evidence that the distribution of earnings changes is affected by downward nominal rigidity in almost all countries. The left tail of the distribution usually appears to exhibit some 'deformation', a spike in the distribution at zero and some thinning in the distribution below zero. However, a purely static descriptive analysis of the shape of the earnings change distribution does not prove the existence of downward nominal wage rigidity, since the thinning of the distribution below zero may simply reflect a peculiar shape of the 'notional' (or 'counterfactual') distribution of earnings changes. As is evident from the exposition of the basic principle of the histogramlocation approach in Section 2, the existence of downward nominal wage rigidity can only be detected by considering the joint variation of location and shape of the earnings change distribution.

\section{Figure 2}

In the literature, usually the median is used as measure of location. However, care must be taken in selecting a measure of location which is not affected by downward nominal wage rigidity. Besides productivity growth, the main determinant of the location of the earnings change distribution is inflation. As can be seen in Figure 3a, inflation has been rather low in many EU countries during the second half of the 90s. As a consequence, in some countries and years (e.g. Denmark in 1999) the median includes zero earnings changes, thereby making it unsuitable as measure of location (see Figure $3 \mathrm{~b}$ ). Throughout the analysis we therefore have to use higher percentiles as measure of location. In Figure 2 for example, the $60^{\text {th }}$ percentile of the earnings change distribution (marked by a thin vertical line) is used as measure for location.

\section{Figure 3}

The descriptive evidence can be used to illustrate the principle of joint variation of location and shape of the earnings change distribution. Greece turns out to be an excellent example for marked joint variation of location and shape. In Greece in the mid-nineties the $60^{\text {th }}$ percentile lies between 12 and 15 percent because of high inflation. When Greece curbed inflation in order to meet the requirements for the introduction of the Euro, the $60^{\text {th }}$ percentile also declined and amounted to only around 3 percent in 2000. This leftward shift of the location of the earnings change distribution is accompanied by a more pronounced pile-up at zero and an increased asymmetry of the distribution due to thinning in the left tail of the distribution. 
As a second example, consider Portugal. The marked asymmetry of the earnings change distribution seems to point to pronounced downward nominal wage rigidity. However, there is hardly any variation of the location of the earnings-change distribution. When we apply the histogram-location approach to the Portuguese data, it will turn out that it is not possible to obtain robust estimates of the extent of downward nominal rigidity for this country on the basis of an isolated national econometric model. Since the same problem also holds for other countries, such as France and Germany, we extend the histogram-location approach (as discussed in Section 2) and estimate pooled models in which the cross-country variation in the location of the earnings-change distribution is used as additional information for the identification of the extent of downward nominal wage rigidity.

As a final example the earnings change distributions for Spain are considered. Spain stands out as the only country in which pronounced changes in location are not accompanied by corresponding changes in the asymmetry of the distribution. Descriptive evidence therefore suggests that Spain is a country where downward nominal wage rigidity seems to play hardly any role, which may come as a surprise.

\section{Empirical implementation and results of the reference specification}

In this section we present national and aggregate European degrees of downward nominal wage rigidity obtained from estimates of our reference specification. The overall reference specification consists of definitions concerning the subsample selection, the histogram construction, the econometric model and the estimation procedure. Since the reference subsample has already been outlined in Section 4, now only the remaining parts of the reference specification are explained.

In the reference histogram construction exact percentage changes, a bin width of two percentage points, and a standardization based on a measure of location $l_{t, i}=q_{60, t, i}$ and a measure of dispersion $v^{80160}$ are used. As in other applications in the literature, e.g. Kahn (1997), exact percentages, rather than log percentages are used, since the transformation implied by using $\log$ percentages are of no consequence due to the non-parametric nature of histograms. The two percent bin width is a compromise between the one percent bin width often used in the literature and even wider bin widths suggested by the usual rules, given the numbers of observations per year and country in our sample. The main consideration behind the use of the standardization of wage changes is the need to use measures of location and dispersion that are unaffected by rigidity, as explained in Section 3. These aspects of histogram construction are varied in Section 7.

As the reference model for estimating an econometric model of the histograms the proportional, pooled, closed model with bins $r=1 \ldots 10$ is used. As discussed in detail in Section 3, this model is best suited for the cross-country analysis. The range of bins chosen is 
somewhat larger than suggested by the range of bins with status changes, $r^{\min }=1$ and $r^{\max }=7$, in order to be able to use the same model in variations of the reference specification where this range increases (narrower bin width).

Finally, our reference estimation procedure is iterated weighted least squares (WLS), where weighing is by equation, i.e. by bins. As a consequence, the smaller bins further out in the left tail of the distribution tend to be estimated more accurately. ${ }^{9}$

After the description of the reference specification we are now able to turn to the estimation results. National and European estimated degrees of rigidity for the reference specification are reported in the first column of Table 3. Degrees of rigidity are highly significant in all of the twelve individual countries included in the sample. While in a majority of seven countries the rigidity coefficient lies between 25 and 50 percent, there are also four countries with lower and one with even higher degree of rigidity, within an overall range of 7 percent (Spain) to 66 percent (Italy). EU wide estimated degrees of rigidity are based on the data of twelve 'old' EU countries, Euro area estimates are based on the data of ten members of the monetary union; both are shown in the lower part of Table 3 . The standard specification results in highly significant estimated rigidity coefficients of 36 per cent and 37 per cent for these two aggregates.

\section{Table 3}

Taking these figures literally means that more than one third of the notional nominal wage reductions for job stayers in the euro area do not take place because of the presence of downward nominal wage rigidity. However, because of the reporting errors typical for survey data, and because of the attenuation effects of these on the observable distribution of per cent wage changes discussed in Knoppik and Beissinger (2003), we interpret these results as constituting lower bounds of true degrees of downward nominal wage rigidity in the respective countries or areas. Actual degrees of downward nominal wage rigidity may turn out to be even larger.

\section{Robustness of the estimation results}

This section deals with the question whether the estimation results for the degree of downward nominal wage rigidity presented in Section 6 are robust to variations in the specification. Those estimates were based on a reference specification which is characterized by definitions regarding (i) the subsample selection, (ii) the histogram construction, (iii) the econo-

9 Iterated seemingly unrelated regression (SUR) is used in Kahn (1997), but was shown to lead to unstable results because of the relatively short length of longitudinal surveys in Beissinger and Knoppik (2001). 
metric model, and (iv) the estimation procedure. ${ }^{10}$ In the following, the robustness of results is checked by varying one by one the characteristics (i) to (iii) of the reference specification, whereas the estimation procedure remains unchanged.

\subsection{Variation of subsample selection}

In principle, estimation results may be influenced by the restrictiveness of subsample selection. As has been explained in Section 4, the subsample selection concerns decisions regarding a) the classification of job stayers, b) the socio-economic characteristics of employees and c) the type of earnings considered in the analysis. The basic idea behind the robustness checks is to choose other subsamples which are either less or more restrictive than the reference subsample used so far in the analysis.

The upper part of Table 4 deals with the variation of the job stayer classification and distinguishes three types of job stayers. The numbering of stayer types from I to III reflects an increase in the restrictiveness of stayer definition with respect to interview distance, absence from work or the main activity in each month between interviews. Choices with respect to these variables may affect the number of observed wage cuts and zero wage changes. The reference subsample used so far in the analysis is based on type-II stayers, who, with regard to sample restrictions lie in between type-I and type-III stayers.

\section{Table 4}

The middle part of Table 4 deals with the variation of socio-economic characteristics and other conditions. Three categories $\mathrm{A}$ to $\mathrm{C}$ are distinguished, with category A representing the least restrictive and category $\mathrm{C}$ the most restrictive sample selection. The selection of the reference subsample corresponds to category B. More restrictive data selection leads to a more homogenous subsample thereby reducing the problem of composition bias in the histogramlocation approach. However, this advantage must be weighted against the disadvantage of loosing too many observations.

The lower part of Table 4 deals with the variation of the earnings measure. Earnings measures 1 and 2 refer to net earnings. However, earnings measure 2 is more restrictive than measure 1 because it is additionally required that the number of reported working hours remains constant. This restriction is also implemented for earnings measure 3, but in this case gross earnings are considered. The estimates of the reference subsample had been based on earnings measure 2 .

10 The reference subsample has been defined in in Section 4, whereas the other aspects of the reference specification are explained in Section 6. 
For the analysis, the three stayer types could, in principle, be combined with each of the selection categories $\mathrm{A}$ to $\mathrm{C}$ and the earnings measures 1 to 3, leading to 27 different subsamples. In our view, however, more insight with respect to the robustness of estimation results can be gained by analyzing the consequences of partial variation of selection criteria. We therefore adopt the following strategy. So far, our focus was on a reference subsample, which represents a 'middle way' with respect to the restrictiveness of sample selection and consists of type-II stayers meeting the requirements of category B and of earnings measure 2 . In the following, we will check the robustness of estimation results for the reference subsample by systematically varying either the stayer definition, or the selection categories, or the earnings measure in comparison to the reference subsample selection.

Table 5 presents the corresponding estimates. From the upper part of the table it can be seen which component of the reference subsample selection has been changed. As a reminder, the first column repeats the specification of the reference subsample. Column 2 reports estimation results if type I stayers are considered instead. ${ }^{11}$ In contrast to type II stayers, no restrictions are imposed for type I stayers with respect to interview distance, absence from work and the monthly activity calendar. Column 3 reports estimation results for type III stayers who face even stronger restrictions with respect to interview distance and absence from work than type II stayers. Consider as an example Denmark. If type I stayers instead of type II stayers are considered, the estimated degree of downward nominal wage rigidity changes from 0.35 (in the reference specification) to 0.39 . If type III stayers are considered instead, the respective value changes to 0.34 . If one also compares the other entries in columns 2 and 3 with column 1, it becomes evident that neither weaker nor stronger restrictions with respect to the stayer definition have a significant impact on the results.

\section{Table 5}

Column 4 presents estimation results for the socio-economic category A instead of category B. In this case female employees are included in the analysis. Moreover, there are weaker (or no) restrictions with respect to sector, type of employment contract and mode of the interview. One would perhaps expect that in this case the extent of downward nominal wage rigidity will be less pronounced. However, with the exception of Italy, where the estimated degree of downward nominal wage rigidity declines from 0.66 in the reference specification to 0.53 , the other estimates tend to remain very close to the estimates of the reference specification and for some countries are even higher. Similar conclusions can be drawn with respect to the results for the more restrictive socio-economic category C (see column 5). Since in this category only male employees working in industry are considered, one would perhaps

11 All other aspects of the reference specification, including the other components of the reference subsample definition, remain unchanged. 
expect that downward nominal wage rigidity will be more pronounced. However, only in the case of Belgium, Greece and Austria significantly higher estimates are observed whereas the estimates for all other countries are close to the estimates in the reference specification.

In column 6, results are reported for earnings measure 1, i.e. in contrast to the reference specification it is not checked whether a change in working hours occurred. In most countries, the estimates of the degree of downward nominal wage rigidity are only slightly lower, with the exception of Italy where the estimated degree of downward nominal wage rigidity changes from 0.66 in the reference specification to 0.53 . In column 7 , gross earnings instead of net earnings are considered. It might be suspected that this change in data selection will considerably modify the earnings change distributions and therefore have a huge impact on the estimation results. However, it is evident from the table that only for four countries the change in estimated wage rigidity seems worth mentioning, with increases in estimated wage rigidity in Denmark and UK, and decreases in Italy and Greece. Overall, from the results documented in Table 5 it can be concluded that the estimates of the reference specification are quite robust to changes in subsample selection.

\subsection{Variation of histogram construction}

Table 6 presents estimates of the degree of downward nominal wage rigidity which were obtained by varying some aspects of histogram construction. As is documented in the upper part of the table, the reference histogram construction used so far had been based on the $60^{\text {th }}$ percentile as measure of location, the difference of $80^{\text {th }}$ and $60^{\text {th }}$ percentile as measure of dispersion (used for standardization) and a bin width of 2 percent (see also Section 6). Column 2 shows that estimates remain basically the same if, all other things being equal, the difference $q_{75}-q_{60}$ is used as measure of dispersion. Columns 3 and 4 present estimates based on histograms with lower or higher bin width (i.e. a bin width of 1.5 percent or 2.5 percent instead of 2 percent). Though the shape of histograms may be influenced by choice of bin width, it is evident from the results that the choice of smaller or larger bins barely affects the estimates. Finally, columns 5 to 7 document that the estimates are quite robust to changes in the measure of location which is used for standardization of histograms. ${ }^{12}$ All in all, it can be concluded from the results in Table 6 that our estimates for the reference specification are robust to changes in histogram construction.

\section{Table 6}

12 Note that for some countries the median must not be used as measure of location because it is affected by downward nominal wage rigidity. For completeness, the results for the median are nevertheless documented. 


\subsection{Variation of econometric model}

Table 7 presents estimates of the degree of downward nominal wage rigidity which were obtained by varying some aspects of the econometric model. As is documented in the upper part of the table, the reference econometric model used so far was based on the pooled closed model described in Section 2 and comprised bins 1 to 10. The second column of the table reports the results of the estimation of isolated national models. Because of insufficient variation of location, the estimation could not be performed for Germany, France, UK and Portugal. The estimates for Ireland and Spain are insignificant. For the remaining countries (with the exception of Belgium) the estimated degree of downward nominal wage rigidity turns out to be higher.

\section{Table 7}

Columns 3 and 4 report the results of estimations which include different bin ranges. As can be seen from the table, a change in the number of bins included (and hence in the number of equations estimated) does barely affect the estimates. The final column presents the results of estimations in which the model has not been closed (see Section 2 for details). This has consequences for the estimation results. For instance, the estimates for Denmark and France are much lower and insignificant. For other countries the significant estimates are considerably higher (UK, Greece, Portugal) or lower (Italy, Germany, Austria, Finland). We conclude that the conventional histogram-location approach in which models are not closed may lead to biased estimates of the extent of downward nominal wage rigidity.

\section{Comparison with results from the literature}

If one tries to put these results in perspective using earlier studies, one encounters the very difficulties that motivate the present project, i.e. difficulties of comparison, in particular (but not only) across method and data, and the scarcity of quantitative European analysis. Nevertheless, it seems worthwhile to see whether and where in the overall spectrum the results do fit in; where there is sufficient overlap with preexisting studies with respect to data and method one can also find corroboration or contradiction. The following considerations are based on the reference specification discussed above. They deal first with the cases where econometric approach and regional coverage overlap and are then completed by the discussion of other European and US evidence. Throughout, the discussion focuses on quantitative econometric rather than purely descriptive or qualitative evidence. ${ }^{13}$

13 A count of zero nominal wage changes is used as the indicator of downward nominal wage rigidity in Dessy (2002); no further identification or econometric estimation of the degree of rigidity are used. In the analyses of UK data of Smith (2000) and Nickell and Quintini (2003) evidence on the extent of DNWR is not based on econometric models; both find small amounts of DNWR. 
As far as Europe or European countries are concerned, the histogram-location approach has only been applied to German data. Beissinger and Knoppik (2001) analyze data of different type, the IAB Beschäftigtenstichprobe, which is a subsample of official social security data, and find degrees of rigidity for blue and white-collar workers that are somewhat below the result for Germany found here. Even more closely related are Knoppik and Dittmar (2002) and Decressin and Decressin (2002), since both studies not only use the histogram-location approach, but apply it to GSOEP data that is the basis of the German part of the ECHP. For a comprehensive measure of earnings, Knoppik and Dittmar (2002) find degrees of rigidity for blue and white collar workers that are close to the results found here. The figures in Decressin and Decressin (2002) are slightly lower. We interpret the German evidence with far reaching overlap with respect to econometric approach and regional coverage as corroboration of the present analysis.

All other econometric European studies of the extent of DNWR use variants of the earnings-function approach introduced by Altonji and Devereux (2000). This approach deals explicitly with measurement error and changing sample composition and claims to yield actual degrees of downward nominal wage rigidity, rather than only lower bounds, which is one reason why estimates should tend to be higher than our ECHP based estimates. ${ }^{14}$ The earningsfunction approach comes in different variants and with a corresponding spectrum of results. Of these variants, the proportional model due to Knoppik and Beissinger (2003) can most easily be compared to results from the histogram-location approach, since it contains a rigidity parameter that can be interpreted in exactly the same way as parameter $\rho$ in the histogram-location approach. Using the mixed measurement error variant of the proportional model, Devicienti (2003) found exactly the same degree of rigidity for Italy as here. With the alternative contaminated mixed measurement variant of the proportional model Knoppik and Beissinger (2003) found more rigidity for Germany than in the present study. Both results are compatible with the interpretation of present results as lower bounds. Ekberg (2004) is an application of the proportional model without any explicit model of measurement error to Swedish data (arguably free of measurement error). Fehr and Goette (2000) is an application of the threshold model to two sets of Swiss data. Both report very high degrees of rigidity for these two European countries outside of our sample. Recently an unsettled issue has emerged within the earnings-function approach, whether and how real wage rigidities should be integrated into the analysis. European studies employing this variant of the earnings-function approach are Fehr, Goette and Pfeiffer (2002) and Bauer, Bonin and Sunde (2003) for Germany, Devicienti, Maida and Sestito (2003) for Italy, and Schweitzer and Barwell (2004) for the UK, which tend to find relatively low degrees of nominal rigidity.

14 Note that the (partial) renunciation on identification by joint variation of location and shape goes along with heavily relying on functional assumptions for identification which may constitute similarly severe problems as the assumptions that are meant to be replaced. 
A comparison with US evidence is easiest with Kahn's application of the histogramlocation approach to PSID data, which are survey data similar to the ECHP. Kahn distinguishes between different types of employees with different compensation systems. She finds no rigidity for salaried employees, but a degree of rigidity of 40 percent for workers who are paid by the hour. The average of these figures is therefore lower than our result for Europe. The opposite is true for a comparison with the results of Lebow u. a. (2003), another application of the histogram-location approach. Even in their version with the most comprehensive earnings measure, estimated degrees of downward nominal wage rigidity are comparable with average European ones and higher than those of anglo-saxon countries in the ECHP European sample. The data in that study is, however, derived from a survey of businesses and therefore not as directly comparable as in the case of the Kahn study. Finally, Altonji and Devereux (2000) use the threshold variant of the earnings-function approach to analyze downward nominal wage rigidity in the PSID to find very high degrees of rigidity. ${ }^{15}$ Overall, there is no conclusive evidence to suggest systematic differences between Europe and the US with respect to downward nominal wage rigidity.

In the few cases, where econometric approach and regional coverage overlap sufficiently for comparisons, our results fit well into the overall picture of existing evidence. Beyond these cases, the European evidence is substantially extended, at the same time allowing consistent cross-country comparisons due to uniform method and uniform data.

\section{Summary, conclusions, and outlook}

This paper analyzes existence and extent of downward nominal wage rigidity in the European Union, which is a question of great significance, both from a theoretical and from a policy perspective. Up until now, evidence on existence and extent of downward nominal wage rigidity in Europe has been limited to only a few countries and, if available, has been hard to compare because different data sources and methodologies have been used. The available evidence has now been substantially extended by the first-time econometric analysis with respect to these questions using employee micro data from the European Community Household Panel (ECHP) for twelve of the EU's current member states.

We develop and apply a pooled multi-country version of the histogram-location approach which exploits variation in the location of the standardized earnings-change distributions over time and over countries and infers existence and extent of downward nominal wage rigidity from the corresponding variation in the shape of observed histograms. This approach allows the estimation of the degree of downward nominal wage rigidity, which is the percentage of notional wage cuts prevented by downward nominal wage rigidity in relation to all notional

15 Other US evidence based on the PSID are McLaughlin (1994) and Christofides and Stengos (2001), which both do not provide quantitative estimates of the degree of downward nominal wage rigidity. 
wage cuts. National and EU wide estimates of this rigidity parameter support the view that downward nominal wage rigidity is a rather widespread phenomenon within the European Union and the Euro Area. Modifications of our reference specification with respect to subsample selection, histogram construction and econometric model reveal that our estimation results are quite robust to changes in the specification. For example, the estimated degree of downward nominal wage rigidity for the Euro area only varies between 0.31 and 0.40 , i.e. between 31 and 40 percent of employees in stable jobs in the Euro area are affected by rigidity.

The estimation results on the national level make evident a considerable variation in the degree of downward nominal wage rigidity across countries despite the comparable data and uniform methodology used. This observation raises the question what determines this country-specific heterogeneity. In the literature, psychological or institutional factors are put forward as possible causes of downward nominal wage rigidity. In a companion paper we strive to identify the role of these factors as possible causes of downward nominal wage rigidity.

\section{References}

Altonji, J. G. and P. J. Devereux (2000) Is there Nominal Wage Rigidity? Evidence from Panel Data, Research in Labor Economics 19, pp. 383-431.

Bauer, T., H. Bonin and U. Sunde (2003) Real and Nominal Wage Rigidities and the Rate of Inflation: Evidence from West German Micro Data, IZA Discussion paper 959, December.

Beissinger, T. and C. Knoppik (2001) Downward Nominal Rigidity in West-German Earnings 19751995, German Economic Review 2 (4), pp. 385-418.

Castellanos, S. G., R. García-Verdú and D. S. Kaplan (2004) Nominal Wage Rigidities in Mexico: Evidence from Social Security Records, NBER Working paper series 10383.

Christofides, L. N. and M. T. Leung (2003) Nominal Wage Rigidity in Contract Data: A Parametric Approach, Economica 70 (280), November, pp. 619-638.

Christofides, L. N. and T. Stengos (2001) A Non-parametric Test of the Symmetry of the PSID Wage-Change Distribution, Economics Letters 71 (3), June, pp. 363-368.

Decressin, A. and J. Decressin (2002) On Sand and the Role of Grease in Labor Markets: How Does Germany Compare? International Monetary Fund, IMF Working Paper 02/164, September.

Dessy, O. (2002) Nominal Wage Rigidity and Institutions: Micro-Evidence from the Europanel, CREST, July.

Devicienti, F. (2003) Downward Nominal Wage Rigidity in Italy: Evidence and Consequences, LABORatorio Riccardo Revelli, LRR working paper series 20, January.

Devicienti, F., A. Maida and P. Sestito (2003) Nominal and Real Wage Rigidity: An Assessment Using Italian Microdata, LABORatorio Riccardo Revelli, LRR working paper series 33, February 4. 
Ekberg, J. (2004) Nominal Wage Rigidity and Real Implications for the Swedisch Labor Market, Stockholm University, February.

EPUNet (2004) ECHP User Guide, 07.07.2004, http://epunet.essex.ac.uk/ECHP USER GUIDE 06-07-2004b.pdf accessed: 10.10.2005.

European Central Bank (2003) Overview of the Background Studies for the Reflections on the ECB's Monetary Policy Strategy, in European Central Bank, ed., Background Studies for the ECB's Evaluation of its Monetary Policy Strategy, Frankfurt a. M.: European Central Bank, pp. 9-30.

Eurostat (2003) ECHP UDB Manual - European Community Household Panel Longitudinal Users'

Database - Waves 1 to 8 - Survey years 1994 to 2001, 1.0. ed., 10.12.2003, DOC. PAN 168, 23 p. http://forum.europa.eu.int/Public/irc/dsis/echpanel/library?l=/user db\&vm=detailed\&sb=Title [download page], accessed: 10.10.2005.

Eurostat (2004) ECHP-Documents, http://forum.europa.eu.int/Public/irc/dsis/echpanel/home [site search page], accessed: 10.10.2005.

Fehr, E. and L. Goette (2000) Robustness and Real Consequences of Nominal Wage Rigidity, Institute for Empirical Research in Economics (IERE), IERE Working Paper 44, May.

Fehr, E., L. Goette and F. Pfeiffer (2002) Dimensions and Consequences of Wage Rigidities in Germany, Zentrum für europäische Wirtschaftsforschung (ZEW), February.

Greene, W. H. (2003) Econometric Analysis, 5. ed., Upper Saddle River, NJ: Prentice Hall.

Holden, S. and F. Wulfsberg (2004) Downward Nominal Wage Rigidity in Europe, University of Oslo and Norges Bank, February.

Kahn, S. (1997) Evidence of Nominal Wage Stickiness from Microdata, American Economic Review 87 (5), pp. 993-1008.

Knoppik, C. (2003) Downward Nominal Rigidity in US Wage Data from the PSID? An Application of the Kernel-Location Approach, University of Regensburg Discussion Papers in Economics 393, December.

Knoppik, C. and T. Beissinger (2003) How Rigid are Nominal Wages? Evidence and Implications for Germany, Scandinavian Journal of Economics 105 (4), pp. 619-641.

Knoppik, C. and T. Beissinger (2005) Downward Nominal Wage Rigidity in Europe - An Analysis of European Micro Data from the ECHP 1994-2001, Bonn: IZA - Institute for the Study of Labor, IZA Discussion Paper 1492, January.

Knoppik, C. and J. Dittmar (2002) A Semi-Parametric Analysis of Downward Nominal Wage Rigidity in the GSOEP 1984-2000, University of Regensburg Discussion Papers in Economics 374, September.

Kramarz, F. (2001) Rigid Wages: What Have we Learnt from Microeconometric Studies, in Drèze J. H., ed., Advances in Macroeconomic Theory, Oxford, UK et al.: Oxford University Press, pp. 194216. 
Lebow, D. E., R. E. Saks and B. A. Wilson (2003) Downward Nominal Wage Rigidity: Evidence from the Employment Cost Index, Advances in Macroeconomics 3 (1 art. 2).

McLaughlin, K. J. (1994) Rigid Wages? Journal of Monetary Economics 34, December, pp. 383414.

Nickell, S. and G. Quintini (2003) Nominal Wage Rigidity and the Rate of Inflation, Economic Journal 113 (490), pp. 762-781.

Peracchi, F. (2002) The European Community Household Panel: A Review, Empirical Economics 27, pp. 63-90.

Rodríguez-Palenzuela, D., G. Camba-Mendez and J. A. Garcia (2003) Relevant economic issues concerning the optimal rate of inflation, European Central Bank, April.

Schweitzer, M. and R. Barwell (2004) The Incidence of Nominal and Real Wage Rigidities in Great Britain: 1978-1998, Federal Reserve Bank of Cleveland and Bank of England.

Smith, J. C. (2000) Nominal Wage Rigidity in the United Kingdom, Economic Journal 110, March, pp. C176-C195.

Stiglbauer, A. (2002) Identification of Wage Rigidities in Microdata - a Critical Literature Review, Focus on Austria (3), pp. 110-126. 


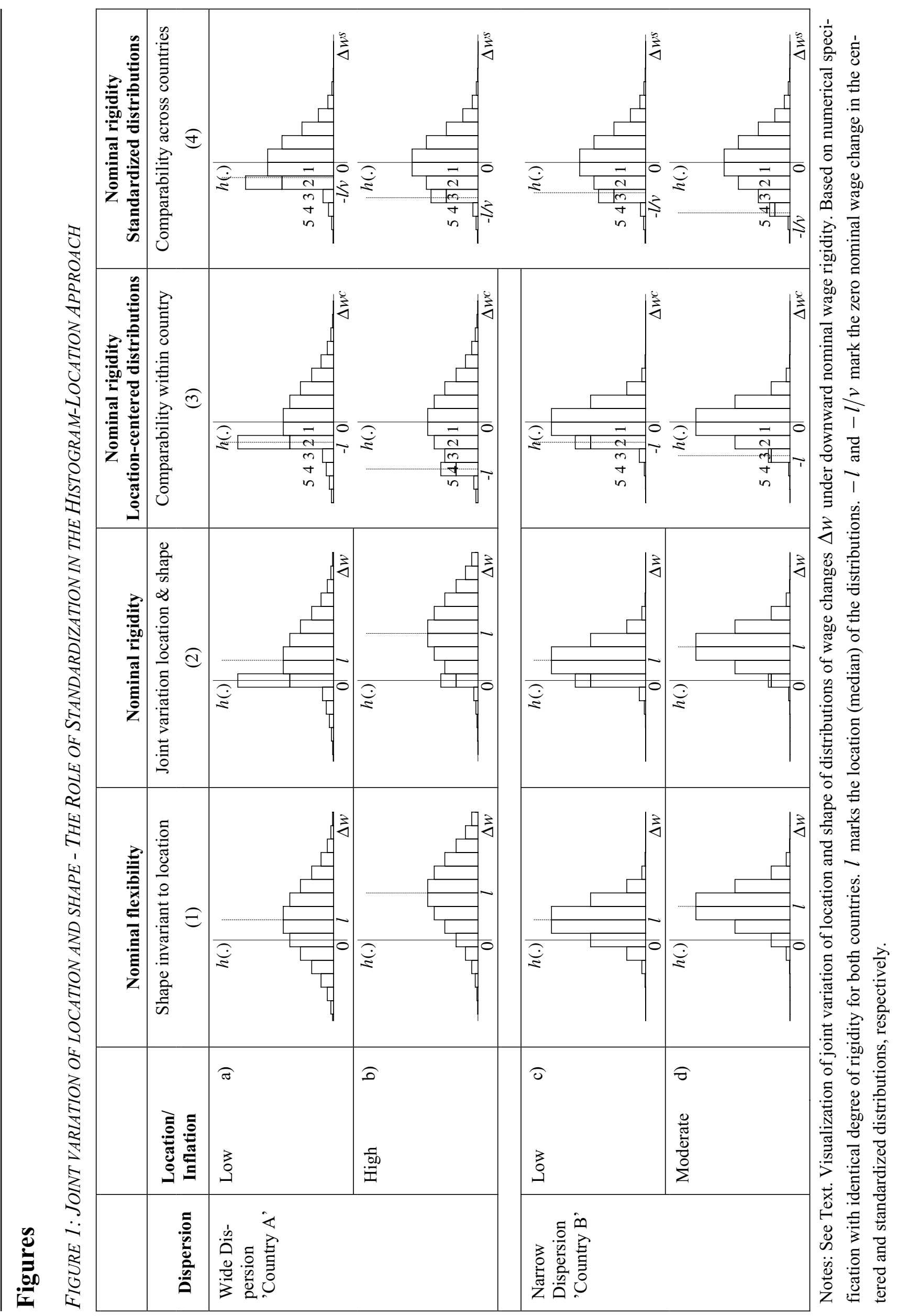



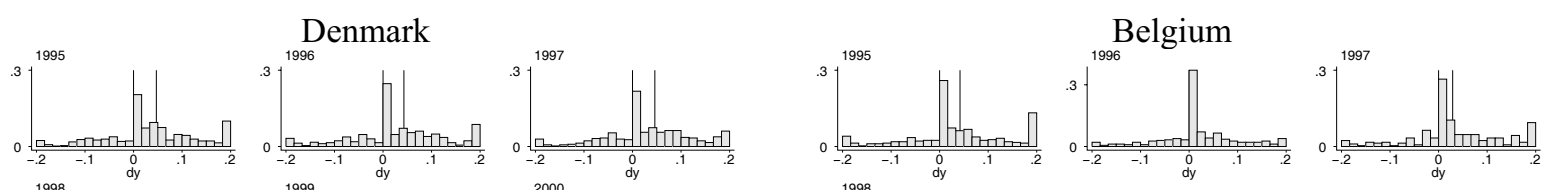

$\int_{0 . \frac{2 n}{2}}^{1998}$

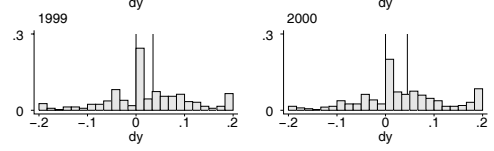

$\underbrace{1998}_{0.2}$

$\int_{0.1}^{2001}$
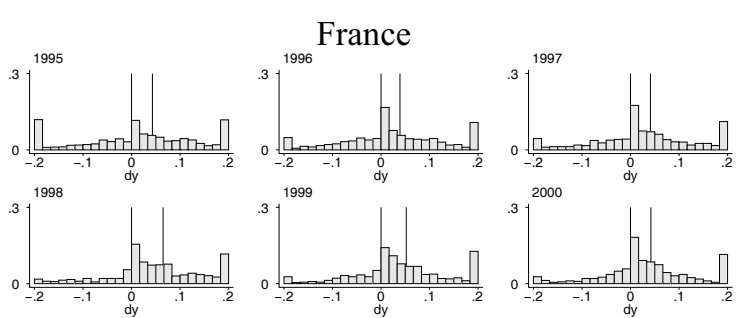

$\int_{0.2}^{2001}$
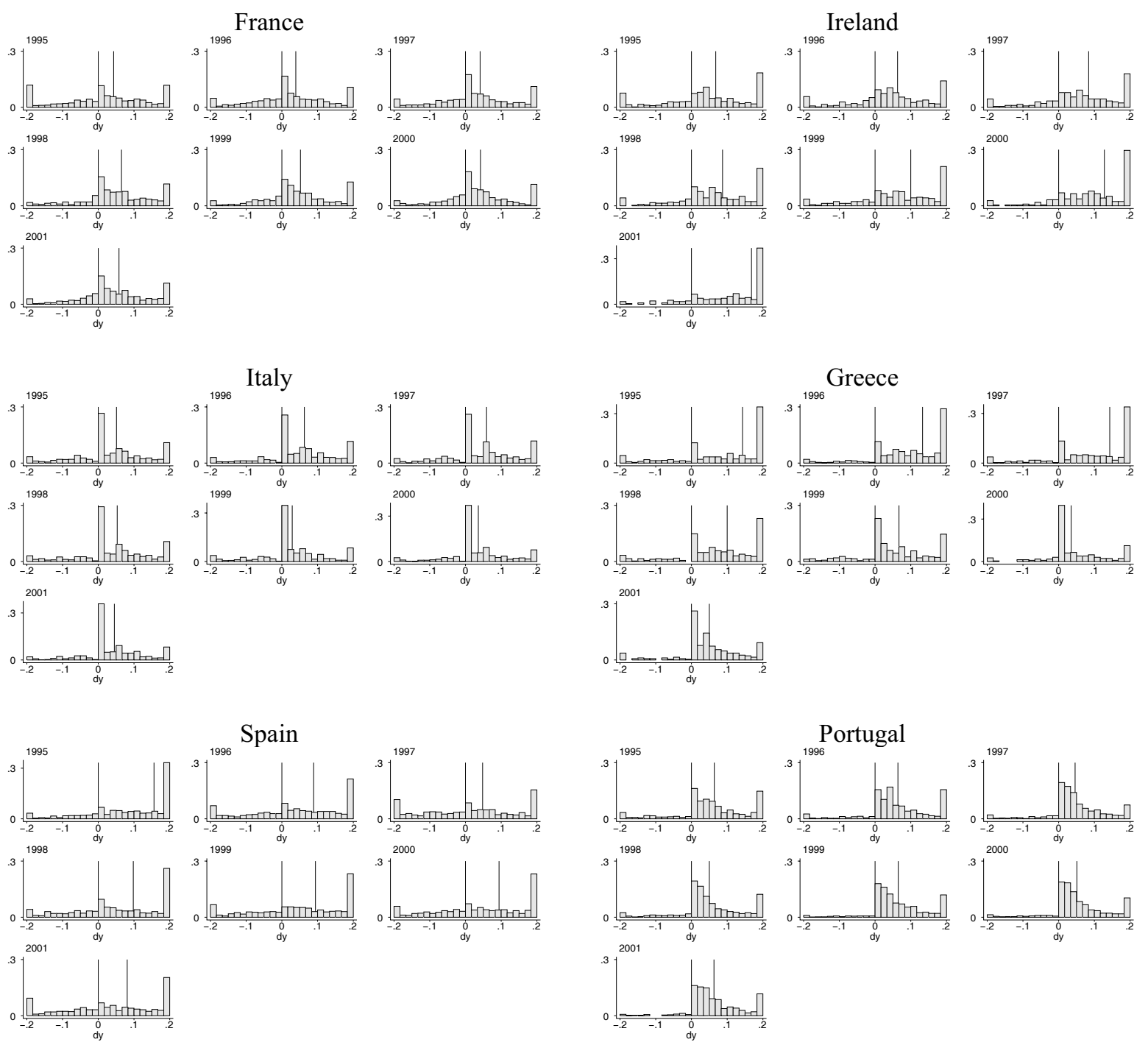

Figure 2 continued on next page 

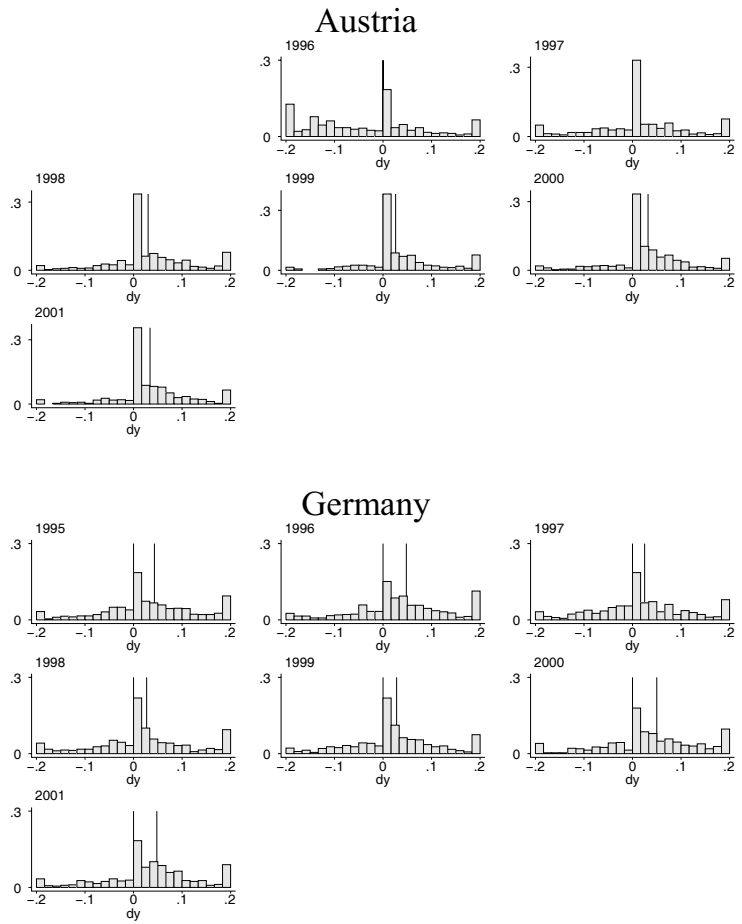

Finland
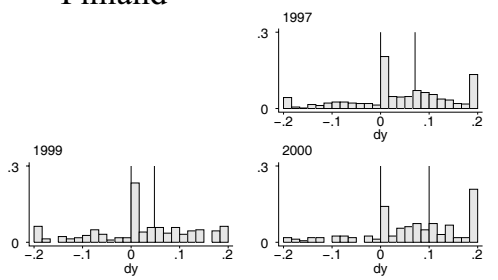
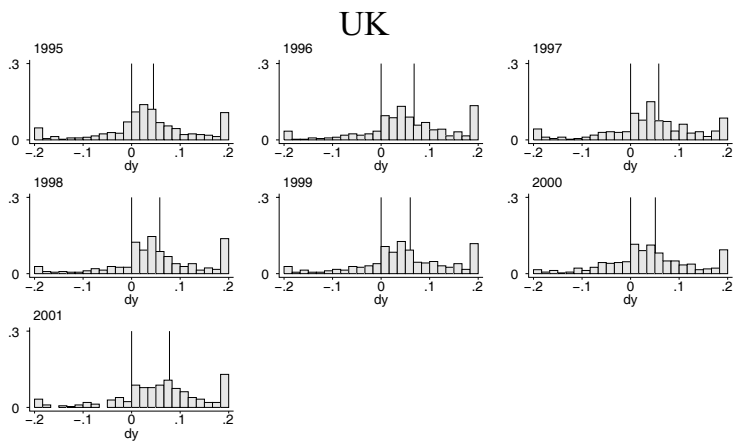

\section{FIGURE 2: HISTOGRAMS OF PER CENT EARNINGS CHANGES BY COUNTRY AND YEAR}

Notes: See text. Exact percentages, bin width $b=.016$, and the country specific, annual $60^{\text {th }}$ percentile $\left(l_{t, i}=q_{60, t, i}\right)$ were used for the construction of histograms. Vertical lines mark zero and the $60^{\text {th }}$ percentile. Changes smaller and larger than -20 and +20 percent are included in the left- and rightmost bins, respectively. Countries are in order of the ECHP identifier of national data sets. 
a) Inflation
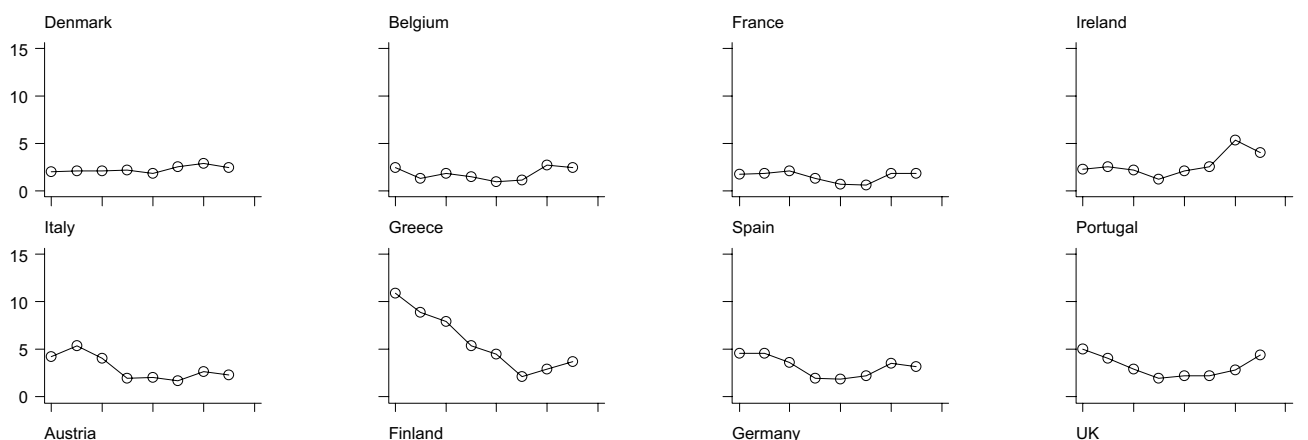

Greece

Spain

Portugal
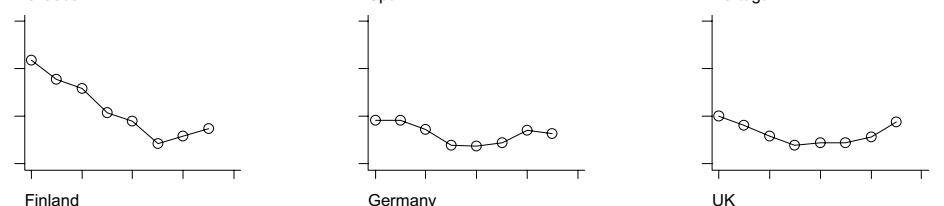

Finlan

Germany
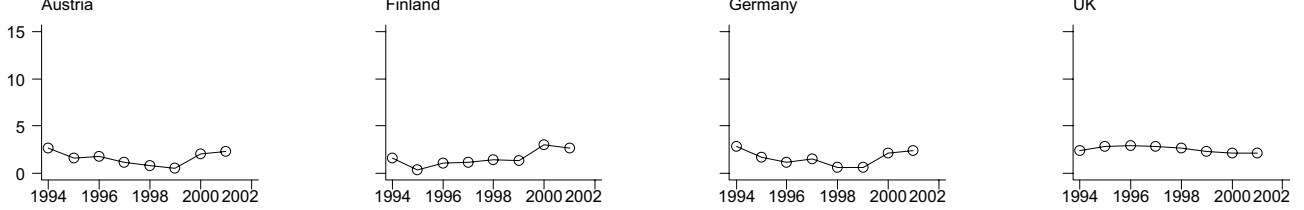

b) Location/Medians
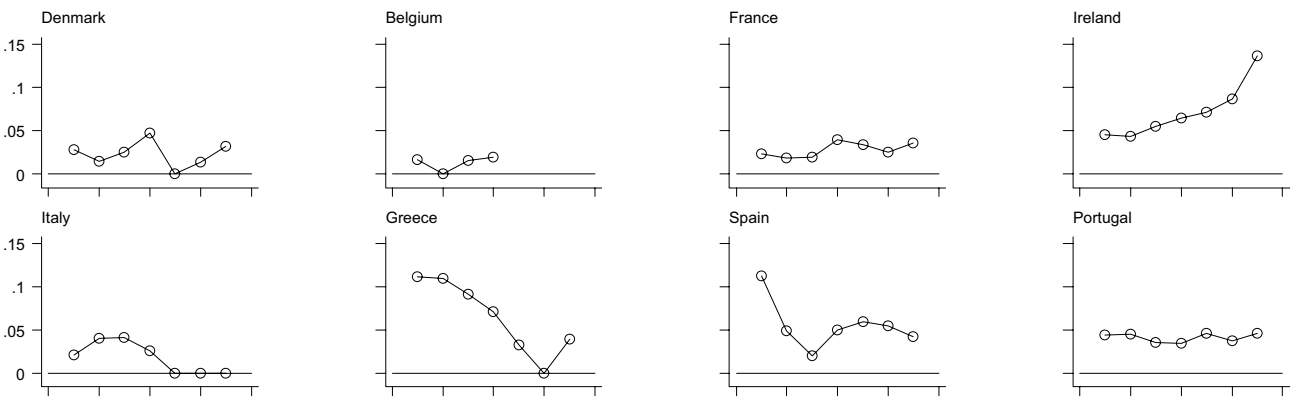

Greece

Spain
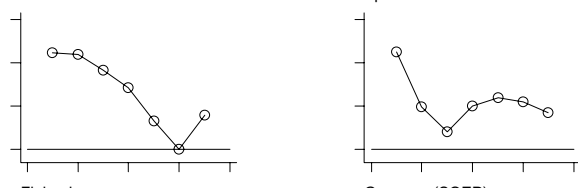

Portuga
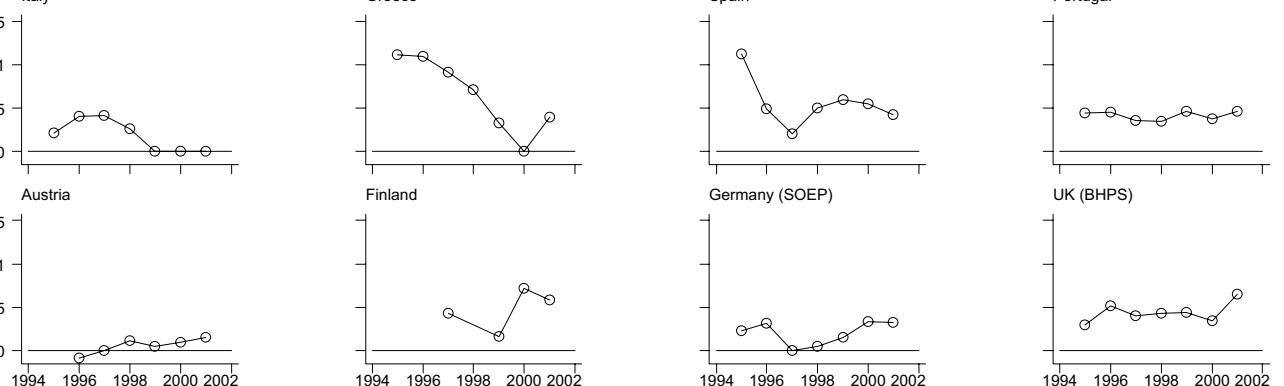

FIGURE 3: RATES OF INFLATION AND LOCATION OF DISTRIBUTIONS OF PER CENT EARNINGS CHANGES BY COUNTRY AND YEAR

a) Consumer Price Index. Source: OECD.

b) Medians of wage change distributions for countries over time. Source: Own computations from ECHP data. Countries are in order of ECHP identifier of national data sets. 


\section{Tables}

TABLE 1: DATA SELECTION FOR REFERENCE SUBSAMPLE

a) Classification of job stayers

\begin{tabular}{lc}
\hline a1) Employment relationship & $\begin{array}{c}\text { Full-time working employees with no } \\
\text { change in job between interviews }\end{array}$ \\
a2) Interview distance $(i d)$ in months & $8 \leq i d \leq 16$ \\
a3) Monthly activity calendar ${ }^{(a)}$ & checked \\
a4) Absence from work $(a b)$ in days $^{(b)}$ & $0 \leq a b \leq 3$
\end{tabular}

b) Socio-economic characteristics and mode of interview

\begin{tabular}{lc}
\hline b1) Age & $21-65$ \\
b2) Sex & male \\
b3) Sector & industry and services \\
b4) Type of employment contract ${ }^{(\mathrm{c})}$ & permanent \\
b5) Mode of interview & no restriction \\
\hline c) Earnings & \\
\hline c1) Type of earnings & monthly net earnings \\
\hline c2) Change in working hours & not allowed \\
\hline
\end{tabular}

Notes: Details on the variables used for data selection can be found in Appendix A of the Discussion Paper version of this paper, Knoppik and Beissinger (2005).

(a) The information of the activity calendar always refers to the year preceding the respective wave year. In order not to lose the data of the final wave, we do not perform a calendar check for the final wave (the year 2001) for the reference subsample.

(b) Absence from work in the last 4 weeks (not counting holiday weeks) due to illness or other reasons. Absence is not checked for UK since information is not available.

(c) The type of employment contract is not checked in 1994 since in that year the information is missing in all countries.

(d) Change in reported working hours in comparison to preceding interview. 
TABLE 2: OBSERVATIONS IN THE REFERENCE SUBSAMPLE

FOR EACH YEAR AND COUNTRY

\begin{tabular}{|c|c|c|c|c|c|c|c|c|c|c|}
\hline Country $^{(a)}$ & 1994 & 1995 & 1996 & 1997 & 1998 & 1999 & 2000 & $2001^{(b)}$ & $\Sigma$ & $T_{c}$ \\
\hline Austria & $\mathrm{X}$ & - & 441 & 805 & 757 & 704 & 456 & 811 & 3,974 & 6 \\
\hline Belgium & - & 640 & 566 & 570 & 510 & (c) 12 & (c) 10 & 486 & 2,794 & 5 \\
\hline Denmark & - & 667 & 564 & 488 & 389 & 423 & 390 & 479 & 3,400 & 7 \\
\hline Finland & $\mathrm{X}$ & $\mathrm{X}$ & - & 699 & (d) 2 & 242 & 238 & 305 & 1,486 & 4 \\
\hline France & - & 1,703 & 1,563 & 1,218 & 1,031 & 939 & 934 & 1,067 & 8,455 & 7 \\
\hline Germany & - & 1,530 & 1,528 & 1,482 & 1,323 & 1,276 & 1,317 & 1,399 & 9,855 & 7 \\
\hline Greece & - & 763 & 631 & 492 & 440 & 565 & 351 & 378 & 3,620 & 7 \\
\hline Ireland & - & 720 & 670 & 626 & 558 & 448 & 311 & 450 & 3,783 & 7 \\
\hline Italy & - & 1,789 & 1,638 & 1,426 & 1,273 & 1,332 & 1,255 & 1,391 & 10,104 & 7 \\
\hline Portugal & - & 1,134 & 1,012 & 1,157 & 1,168 & 1,182 & 901 & 1,334 & 7,888 & 7 \\
\hline Spain & - & 1,224 & 1,087 & 1,027 & 1,005 & 1,007 & 1,014 & 1,183 & 7,547 & 7 \\
\hline UK & - & 947 & 974 & 929 & 927 & 877 & 819 & 935 & 6,408 & 7 \\
\hline$\Sigma$ & - & 11,117 & 10,674 & 10,919 & 9,383 & 9,007 & 7,996 & 11,143 & 70,239 & 78 \\
\hline
\end{tabular}

Notes: The table contains the number of observed per cent changes of monthly net earnings between two consecutive interview dates in the reference subsample as defined in Table 1. For cells marked with an X the respective wave is not available. In cells marked with a dash observations are missing since information on the preceding year is not available. $T_{c}$ denotes the number of observed histograms for country $c$.

(a) Sweden, Luxembourg and the Netherlands are excluded from the analysis (see text).

(b) We leave the year 2001 in the reference subsample though the monthly activity calendar cannot be checked for the final wave. This explains the rise in observations for the last wave.

(c) The low number of observations in Belgium in 1999 and 2000 is due to the fact that in 1999 the sector information is missing in most cases.

(d) The low number of observations in Finland in 1998 is due to the fact that the spell between interviews exceeded the upper limit of 16 months for most observations in 1998. 
TABLE 3: ESTIMATED DEGREES OF DOWNWARD NOMINAL WAGE RIGIDITY

\begin{tabular}{|c|c|c|c|c|}
\hline & & \multicolumn{2}{|c|}{ Degree of rigidity } & \multirow{2}{*}{$\begin{array}{c}\begin{array}{c}\text { Range of } \\
\text { degree of rigidity }^{(\mathrm{b})}\end{array} \\
\rho \\
\end{array}$} \\
\hline & & $\rho$ & $t$-values & \\
\hline & & (1) & (2) & (3) \\
\hline \multirow[t]{12}{*}{ National } & Austria & (a) 0.45 & (16.36) & {$[0.41,0.52]$} \\
\hline & Belgium & 0.47 & (13.47) & {$[0.41,0.68]$} \\
\hline & Denmark & 0.35 & (12.49) & {$[0.31,0.60]$} \\
\hline & Finland & 0.46 & (12.99) & {$[0.36,0.52]$} \\
\hline & France & 0.23 & $(7.54)$ & {$[0.20,0.28]$} \\
\hline & Germany & 0.28 & $(9.42)$ & {$[0.19,0.33]$} \\
\hline & Greece & 0.43 & (16.86) & {$[0.36,0.64]$} \\
\hline & Ireland & 0.18 & $(7.03)$ & {$[0.00,0.20]$} \\
\hline & Italy & 0.66 & (22.38) & {$[0.45,0.89]$} \\
\hline & Portugal & 0.41 & (15.13) & {$[0.37,0.54]$} \\
\hline & Spain & 0.07 & $(2.60)$ & {$[0.00,0.10]$} \\
\hline & UK & 0.14 & $(5.32)$ & {$[0.10,0.24]$} \\
\hline \multirow[t]{2}{*}{ European } & $\mathrm{EU}^{(\mathrm{c})}$ & 0.36 & $(25.17)$ & {$[0.30,0.37]$} \\
\hline & Euro area ${ }^{(\mathrm{c})}$ & 0.37 & $(24.19)$ & {$[0.31,0.40]$} \\
\hline
\end{tabular}

Notes: Column 1 contains estimated national and aggregate rigidity coefficients $\rho$ from closed pooled models for the reference specification. These estimates are based on $N=780$ observed bin sizes. The coefficient $\rho$ captures the degree of downward nominal wage rigidity in the sense that it measures the share of counterfactual wage cuts that are prevented by nominal rigidity. Column 3 contains the range of $\rho$ that results from systematic variation of the reference specification. The reference specification and its variations consist of definitions with respect to subsample used, histogram construction, econometric model, and estimation that are detailed in the text.

(a) Assumption of measure of location greater than (nominal) zero violated at least in one year; see also Section 2.

(b) Ranges for the degree of rigidity consist of the minima and maxima of estimated $\rho$ over the variations of the reference specification, except the inconsistent estimates from the non-closed model. Insignificant estimates in the case of Ireland and Spain are represented by a zero lower bound of the range.

(c) The European Union (EU) estimate is based on twelve of the fifteen old European Union countries (without Luxembourg, the Netherlands, and Sweden). The Euro area estimate is based on ten of the twelve current member states of the European monetary union (without Luxembourg and the Netherlands). 
TABLE 4: VARIATION OF SUBSAMPLE SELECTION

\section{a) Classification of job stayers}

Reference subsample
Restrictiveness of sample selection
a1) Employment relationship
a2) Interview distance (id) in months
a3) Monthly activity calendar
a4) Absence from work ( $a b)$ in days

b) Socio-economic characteristics and mode of interview

Reference subsample

Restrictiveness of sample selection

b1) Age

b2) Sex

b3) Sector

b4) Type of employment contract

b5) Mode of interview
Type I

Type II

Type III

$\mathrm{X}$

low middle high

Full-time working employees with no change in job between interviews
no restriction
$8 \leq i d \leq 16$
$11 \leq i d \leq 13$
not checked
checked $^{(\mathrm{b})}$
checked $^{(\mathrm{b})}$
no restriction
$0 \leq a b \leq 3^{(\mathrm{a})}$

$a b=0^{(a)}$

\begin{tabular}{lccc} 
& Earnings & sonal interview $^{(\mathrm{e})}$ & Earnings \\
c) Earnings & measure 1 & measure 2 & $\begin{array}{c}\text { Earnings } \\
\text { measure 3 }\end{array}$ \\
\hline Reference subsample & low & X & high \\
Restrictiveness of sample selection & monthly net & honthly net & monthly gross \\
c1) Type of earnings & $\begin{array}{c}\text { earnings } \\
\text { earnings }\end{array}$ & $\begin{array}{c}\text { earnings } \\
\text { not allowed }\end{array}$ & not allowed $^{(\mathrm{d})}$
\end{tabular}

Notes: Details on the variables used for data selection can be found in Appendix A of the Discussion Paper version of this paper, Knoppik and Beissinger (2005). The reference subsample consists of type-II stayers meeting the requirements of category B and earnings measure 2.

(a)-(d) See notes in Table 1.

(e) Since it is missing or wrongly coded, this information could not be checked for France and the Netherlands for any year and neither for Portugal in 1994. 


\section{TABLE 5: ESTIMATED DEGREES OF RIGIDITY - VARIATION OF SUBSAMPLE}

\begin{tabular}{|c|c|c|c|c|c|c|c|}
\hline \multirow[b]{2}{*}{ Subsample } & Reference $^{(\mathrm{d})}$ & \multicolumn{2}{|c|}{ Stayer type } & \multicolumn{2}{|c|}{ Soc.econ. Category } & \multicolumn{2}{|c|}{ Earn. Meas. } \\
\hline & reference & & & & & & \\
\hline Stayer type & II & I & III & & & & \\
\hline Soc.-ec. Cat. & B & & & A & $\mathrm{C}$ & & \\
\hline Earn. Meas. & 2 & & & & & 1 & 3 \\
\hline Data treat. & reference & reference & reference & reference & reference & reference & reference \\
\hline \multirow[t]{2}{*}{ Model } & reference & reference & reference & reference & reference & reference & reference \\
\hline & $(1)$ & (2) & (3) & (4) & $(5)$ & (6) & (7) \\
\hline \multirow[t]{2}{*}{ Germany } & 0.28 & 0.28 & 0.27 & 0.31 & 0.33 & 0.26 & 0.31 \\
\hline & $(9.42)$ & $(10.60)$ & $(9.39)$ & $(10.38)$ & (10.37) & (11.14) & $(9.89)$ \\
\hline \multirow{2}{*}{ Denmark } & 0.35 & 0.39 & 0.34 & 0.31 & 0.36 & 0.32 & 0.45 \\
\hline & (12.49) & $(15.07)$ & (10.96) & $(9.81)$ & (11.15) & (13.89) & $(15.91)$ \\
\hline \multirow[t]{2}{*}{ Belgium } & 0.47 & 0.46 & 0.48 & 0.47 & 0.68 & 0.47 & 0.41 \\
\hline & (13.47) & (13.69) & $(12.41)$ & $(14.80)$ & $(7.36)$ & $(14.62)$ & $(10.24)$ \\
\hline \multirow[t]{2}{*}{ France } & 0.23 & 0.24 & 0.24 & 0.28 & 0.23 & 0.20 & 0.20 \\
\hline & (7.54) & $(9.10)$ & $(8.20)$ & $(8.60)$ & $(7.35)$ & (9.14) & $(6.37)$ \\
\hline \multirow[t]{2}{*}{ UK } & 0.14 & 0.15 & 0.12 & 0.19 & 0.13 & 0.14 & 0.24 \\
\hline & (5.32) & (6.42) & (5.17) & $(6.75)$ & $(4.01)$ & (6.49) & (8.17) \\
\hline \multirow[t]{2}{*}{ Ireland } & 0.18 & 0.14 & 0.11 & 0.18 & 0.11 & 0.12 & 0.20 \\
\hline & (7.03) & (5.95) & $(4.08)$ & (7.66) & $(2.79)$ & (5.47) & (6.93) \\
\hline \multirow[t]{2}{*}{ Italy } & 0.66 & 0.68 & 0.62 & 0.53 & 0.58 & 0.53 & 0.45 \\
\hline & (22.38) & (26.79) & (19.67) & (15.77) & (17.34) & (21.91) & (14.71) \\
\hline \multirow[t]{2}{*}{ Greece } & 0.43 & 0.43 & 0.46 & 0.51 & 0.57 & 0.42 & 0.36 \\
\hline & (16.86) & (17.64) & (10.43) & (17.44) & (16.33) & (18.34) & (12.36) \\
\hline \multirow[t]{2}{*}{ Spain } & 0.07 & 0.08 & 0.07 & 0.05 & 0.10 & 0.05 & 0.02 \\
\hline & (2.60) & (3.53) & $(2.91)$ & (1.69) & (3.10) & (2.05) & $(0.65)$ \\
\hline \multirow[t]{2}{*}{ Portugal } & 0.41 & 0.40 & 0.40 & 0.54 & 0.46 & 0.39 & 0.43 \\
\hline & (15.13) & (16.48) & (16.36) & (17.14) & (13.78) & (17.69) & (13.93) \\
\hline \multirow[t]{2}{*}{ Austria $^{(a)}$} & 0.45 & 0.49 & 0.43 & 0.43 & 0.60 & 0.41 & 0.47 \\
\hline & (16.36) & (18.21) & (15.00) & (14.33) & (17.33) & (17.06) & (15.14) \\
\hline \multirow[t]{2}{*}{ Finland } & 0.46 & 0.43 & 0.47 & 0.45 & 0.46 & 0.43 & 0.52 \\
\hline & $(12.99)$ & $(15.80)$ & $(11.65)$ & $(12.99)$ & $(5.42)$ & $(14.76)$ & (13.69) \\
\hline \multirow[t]{2}{*}{$\mathrm{EU}^{(\mathrm{c})}$} & 0.36 & 0.36 & 0.32 & 0.33 & 0.36 & 0.30 & 0.33 \\
\hline & (25.17) & (26.06) & (21.95) & (22.69) & (21.46) & $(25.20)$ & (22.88) \\
\hline \multirow[t]{2}{*}{ Euro area $^{(\mathrm{c})}$} & 0.37 & 0.37 & 0.33 & 0.35 & 0.40 & 0.31 & 0.32 \\
\hline & $(24.19)$ & $(23.72)$ & (20.64) & $(21.56)$ & (21.19) & $(23.30)$ & (18.66) \\
\hline
\end{tabular}

Notes: The table contains estimated national and aggregate degrees of rigidity (parameter $\rho_{j}, t$-values in parentheses) for variations of the reference specification with respect to the reference subsample. See Section 7 for discussion.

(a,c) See Table 3 for explanations of these table footnotes.

(d) Results for reference specification (Table 3) repeated for convenience. 


\section{TABLE 6: ESTIMATED DEGREES OF RIGIDITY - VARIATION OF HISTOGRAM CONSTRUCTION}

\begin{tabular}{|c|c|c|c|c|c|c|c|}
\hline \multirow[b]{2}{*}{ Subsample } & \multirow{2}{*}{$\frac{\text { Reference }^{(\mathrm{d})}}{\text { reference }}$} & \multirow{2}{*}{$\frac{\text { Stand. }}{\text { reference }}$} & \multicolumn{2}{|c|}{ Bin width } & \multicolumn{3}{|c|}{ Location } \\
\hline & & & reference & reference & reference & reference & reference \\
\hline Hist. constr. & reference & & & & & & \\
\hline Dispersion & $q_{80}-l o c$ & $q_{75}-l o c$ & & & & & \\
\hline Bin width & .020 & & .015 & .025 & & & \\
\hline Location & $q_{60}$ & & & & $q_{50}$ & $q_{55}$ & $q_{65}$ \\
\hline \multirow[t]{2}{*}{ Model } & reference & reference & reference & reference & reference & reference & reference \\
\hline & (1) & (2) & (3) & (4) & (5) & (6) & (7) \\
\hline \multirow[t]{2}{*}{ Germany } & 0.28 & 0.28 & 0.31 & 0.26 & (a) 0.27 & 0.28 & 0.31 \\
\hline & $(9.42)$ & $(9.41)$ & (12.90) & $(7.81)$ & (9.14) & (8.97) & (12.90) \\
\hline \multirow[t]{2}{*}{ Denmark } & 0.35 & 0.37 & 0.41 & 0.32 & (a) 0.32 & 0.33 & 0.41 \\
\hline & (12.49) & (12.34) & (17.12) & $(9.96)$ & (10.65) & $(10.52)$ & (17.08) \\
\hline \multirow[t]{2}{*}{ Belgium } & 0.47 & 0.48 & 0.48 & 0.45 & (a) 0.44 & (a) 0.45 & 0.48 \\
\hline & (13.47) & (14.08) & (14.68) & (11.43) & (11.10) & (11.36) & (13.64) \\
\hline \multirow[t]{2}{*}{ France } & 0.23 & 0.22 & 0.21 & 0.22 & 0.24 & 0.23 & 0.21 \\
\hline & $(7.54)$ & $(6.95)$ & $(8.75)$ & (6.69) & $(8.01)$ & $(7.36)$ & (8.05) \\
\hline \multirow[t]{2}{*}{ UK } & 0.14 & 0.17 & 0.10 & 0.17 & 0.18 & 0.17 & 0.12 \\
\hline & $(5.32)$ & $(5.67)$ & $(4.86)$ & (5.37) & (6.11) & $(5.76)$ & (4.74) \\
\hline \multirow[t]{2}{*}{ Ireland } & 0.18 & 0.18 & 0.14 & 0.20 & 0.19 & 0.19 & 0.12 \\
\hline & (7.03) & $(6.09)$ & $(6.09)$ & $(6.77)$ & (6.54) & $(6.15)$ & (5.10) \\
\hline \multirow[t]{2}{*}{ Italy } & 0.66 & 0.66 & 0.70 & 0.57 & (a) 0.56 & 0.58 & 0.64 \\
\hline & (22.38) & (21.12) & (27.98) & (17.06) & (18.83) & (18.77) & (23.33) \\
\hline \multirow[t]{2}{*}{ Greece } & 0.43 & 0.48 & 0.45 & 0.43 & (a) 0.50 & 0.48 & 0.44 \\
\hline & $(16.86)$ & (16.92) & $(20.53)$ & (15.17) & (16.18) & (14.80) & (18.41) \\
\hline \multirow[t]{2}{*}{ Spain } & 0.07 & 0.07 & 0.07 & 0.04 & 0.07 & 0.04 & 0.10 \\
\hline & $(2.60)$ & $(2.24)$ & $(3.02)$ & (1.18) & (2.17) & $(1.26)$ & (4.39) \\
\hline \multirow[t]{2}{*}{ Portugal } & 0.41 & 0.44 & 0.38 & 0.46 & 0.48 & 0.42 & 0.37 \\
\hline & (15.13) & $(15.22)$ & (17.28) & $(15.20)$ & (15.85) & (13.52) & (16.40) \\
\hline \multirow[t]{2}{*}{ Austria $^{(a)}$} & 0.45 & 0.44 & 0.50 & 0.42 & 0.47 & 0.48 & 0.50 \\
\hline & (16.36) & (16.34) & (21.67) & (13.36) & (13.61) & (14.77) & (18.96) \\
\hline \multirow[t]{2}{*}{ Finland } & 0.46 & 0.42 & 0.45 & 0.42 & 0.36 & 0.41 & 0.48 \\
\hline & (12.99) & (11.67) & (16.17) & (11.23) & (8.77) & $(9.55)$ & (14.41) \\
\hline \multirow[t]{2}{*}{$\mathrm{EU}^{(\mathrm{c})}$} & 0.36 & 0.37 & 0.37 & 0.34 & 0.33 & 0.33 & 0.34 \\
\hline & (25.17) & (26.07) & $(28.30)$ & (22.59) & (21.30) & (20.22) & (26.10) \\
\hline \multirow[t]{2}{*}{ Euro area $^{(\mathrm{c})}$} & 0.37 & 0.39 & 0.38 & 0.36 & 0.35 & 0.34 & 0.34 \\
\hline & (24.19) & $(24.56)$ & $(27.42)$ & (21.73) & $(20.20)$ & (18.72) & (24.06) \\
\hline
\end{tabular}

Notes: The table contains estimated national and aggregate degrees of rigidity (parameter $\rho_{j}, t$-values in parentheses) for variations of the reference specification with respect to reference histogram construction. See Section 7 for discussion.

(a,c) See Table 3 for explanations of these table footnotes.

(d) Results for reference specification (Table 3) repeated for convenience. 


\section{TABLE 7: ESTIMATED DEGREES OF RIGIDITY - VARIATION OF MODEL}

\begin{tabular}{|c|c|c|c|c|c|}
\hline \multirow[b]{2}{*}{ Subsample } & \multirow{2}{*}{$\begin{array}{c}\text { Reference }^{(\mathrm{d})} \\
\text { reference }\end{array}$} & \multirow{2}{*}{$\begin{array}{c}\text { Pooled } \\
\text { reference }\end{array}$} & \multicolumn{2}{|c|}{ Bin range } & \multirow{2}{*}{$\begin{array}{c}\text { Closed } \\
\text { reference }\end{array}$} \\
\hline & & & reference & reference & \\
\hline Hist. constr. & reference & reference & reference & reference & reference \\
\hline Model & reference & & & & \\
\hline Pooled & yes & no & & & \\
\hline Bin range & $1 . .10$ & & $1 . .12$ & $1 . .8$ & \\
\hline Small changes & no & & & & \\
\hline \multirow[t]{2}{*}{ Closed } & yes & & & & no \\
\hline & $(1)$ & (2) & (3) & (4) & (5) \\
\hline \multirow[t]{2}{*}{ Germany } & 0.28 & $-($ b) & 0.27 & 0.29 & 0.19 \\
\hline & $(9.42)$ & & (9.18) & $(9.84)$ & $(2.79)$ \\
\hline \multirow[t]{2}{*}{ Denmark } & 0.35 & 0.60 & 0.35 & 0.37 & 0.09 \\
\hline & (12.49) & $(5.87)$ & (12.36) & (13.31) & $(1.17)$ \\
\hline \multirow[t]{2}{*}{ Belgium } & 0.47 & 0.41 & 0.47 & 0.46 & 0.38 \\
\hline & (13.47) & (2.16) & (13.83) & (12.82) & $(5.29)$ \\
\hline \multirow[t]{2}{*}{ France } & 0.23 & $-(b)$ & 0.23 & 0.22 & 0.13 \\
\hline & $(7.54)$ & & (7.51) & $(7.50)$ & $(1.75)$ \\
\hline \multirow[t]{2}{*}{ UK } & 0.14 & - (b) $^{-1}$ & 0.16 & 0.12 & 0.24 \\
\hline & $(5.32)$ & & (5.98) & $(4.84)$ & $(3.76)$ \\
\hline \multirow[t]{2}{*}{ Ireland } & 0.18 & -0.10 & 0.19 & 0.17 & 0.14 \\
\hline & $(7.03)$ & $(-1.32)$ & (7.32) & $(6.57)$ & $(2.01)$ \\
\hline \multirow[t]{2}{*}{ Italy } & 0.66 & 0.89 & 0.63 & 0.68 & 0.41 \\
\hline & $(22.38)$ & (2.87) & (21.36) & (23.39) & $(6.65)$ \\
\hline \multirow[t]{2}{*}{ Greece } & 0.43 & 0.64 & 0.43 & 0.43 & 0.58 \\
\hline & (16.86) & (13.93) & (16.91) & (16.65) & $(9.73)$ \\
\hline \multirow[t]{2}{*}{ Spain } & 0.07 & -0.01 & 0.06 & 0.08 & -0.20 \\
\hline & $(2.60)$ & $(-0.29)$ & (2.33) & $(2.98)$ & $-(2.24)$ \\
\hline \multirow[t]{2}{*}{ Portugal } & 0.41 & - (b) & 0.44 & 0.38 & 0.69 \\
\hline & (15.13) & & (15.84) & (14.40) & (11.98) \\
\hline \multirow[t]{2}{*}{ Austria $^{(a)}$} & 0.45 & 0.85 & 0.44 & 0.49 & 0.31 \\
\hline & (16.36) & (8.84) & (15.96) & (17.18) & $(5.02)$ \\
\hline \multirow[t]{2}{*}{ Finland } & 0.46 & 0.52 & 0.44 & 0.46 & 0.20 \\
\hline & $(12.99)$ & $(7.6)$ & $(12.77)$ & $(13.01)$ & $(2.36)$ \\
\hline \multirow[t]{2}{*}{$\mathrm{EU}^{(\mathrm{c})}$} & 0.36 & - & 0.36 & 0.36 & 0.46 \\
\hline & $(25.17)$ & - & $(25.17)$ & (25.17) & (13.14) \\
\hline \multirow[t]{2}{*}{ Euro area ${ }^{(c)}$} & 0.37 & - & 0.37 & 0.37 & 0.40 \\
\hline & $(24.19)$ & - & $(24.19)$ & $(24.19)$ & (7.66) \\
\hline
\end{tabular}

Notes: The table contains estimated national and aggregate degrees of rigidity (parameter $\rho_{j}, t$-values in parentheses) for variations of the reference specification with respect to the reference econometric model. See Section 7 for discussion.

(a,c) See Table 3 for explanations of these footnotes.

(b) Estimation not feasible for this specification because of the insufficient variation in location that is reflected in $r_{j}^{\max }-r_{j}^{\min } \leq 1$.

(d) Results for reference specification (Table 3) repeated for convenience. 
DISKUSSIONSBEITRÄGE AUS DEM

INSTITUT FÜR VOLKSWIRTSCHAFTSLEHRE

DER UNIVERSITÄT HOHENHEIM

Nr. 220/2003 Walter Piesch, Ein Überblick über einige erweiterte Gini-Indices

Eigenschaften, Zusammenhänge, Interpretationen

Nr. 221/2003 Ansgar Belke, Hysteresis Models and Policy Consulting

Nr. 222/2003 Ansgar Belke and Daniel Gros, Does the ECB Follow the FED? Part II September $11^{\text {th }}$ and the Option Value of Waiting

Nr. 223/2003 Ansgar Belke and Matthias Göcke, Monetary Policy (In-) Effectiveness under Uncertainty Some Normative Implications for European Monetary Policy

Nr. 224/2003 Walter Piesch, Ein Vorschlag zur Kombination von P - und M - Indices in der Disparitätsmessung

Nr. $\quad$ 225/2003 Ansgar Belke, Wim Kösters, Martin Leschke and Thorsten Polleit, Challenges to ECB Credibility

Nr. 226/2003 Heinz-Peter Spahn, Zum Policy-Mix in der Europäischen Währungsunion

Nr. $\quad$ 227/2003 Heinz-Peter Spahn, Money as a Social Bookkeeping Device

From Mercantilism to General Equilibrium Theory

Nr. 228/2003 Ansgar Belke, Matthias Göcke and Martin Hebler, Institutional Uncertainty and European Social Union: Impacts on Job Creation and Destruction in the CEECs.

Nr. 229/2003 Ansgar Belke, Friedrich Schneider, Privatization in Austria: Some Theoretical Reasons and First Results About the Privatization Proceeds

Nr. 230/2003 Ansgar Belke, Nilgün Terzibas, Die Integrationsbemühungen der Türkei aus ökonomischer Sicht

Nr. 231/2003 Ansgar Belke, Thorsten Polleit, 10 Argumente gegen eine Euro-US-DollarWechselkursmanipulation

Nr. 232/2004 Ansgar Belke, Kai Geisslreither and Daniel Gros, On the Relationship Between Exchange Rates and Interest Rates: Evidence from the Southern Cone

Nr. 233/2004 Lars Wang, IT-Joint Ventures and Economic Development in ChinaAn Applied General Equilibrium Analysis

Nr. 234/2004 Ansgar Belke, Ralph Setzer, Contagion, Herding and Exchange Rate Instability - A Survey

Nr. 235/2004 Gerhard Wagenhals, Tax-benefit microsimulation models for Germany: A Survey

Nr. 236/2004 Heinz-Peter Spahn, Learning in Macroeconomics and Monetary Policy:

The Case of an Open Economy

Nr. 237/2004 Ansgar Belke, Wim Kösters, Martin Leschke and Thorsten Polleit, Liquidity on the Rise - Too Much Money Chasing Too Few Goods 


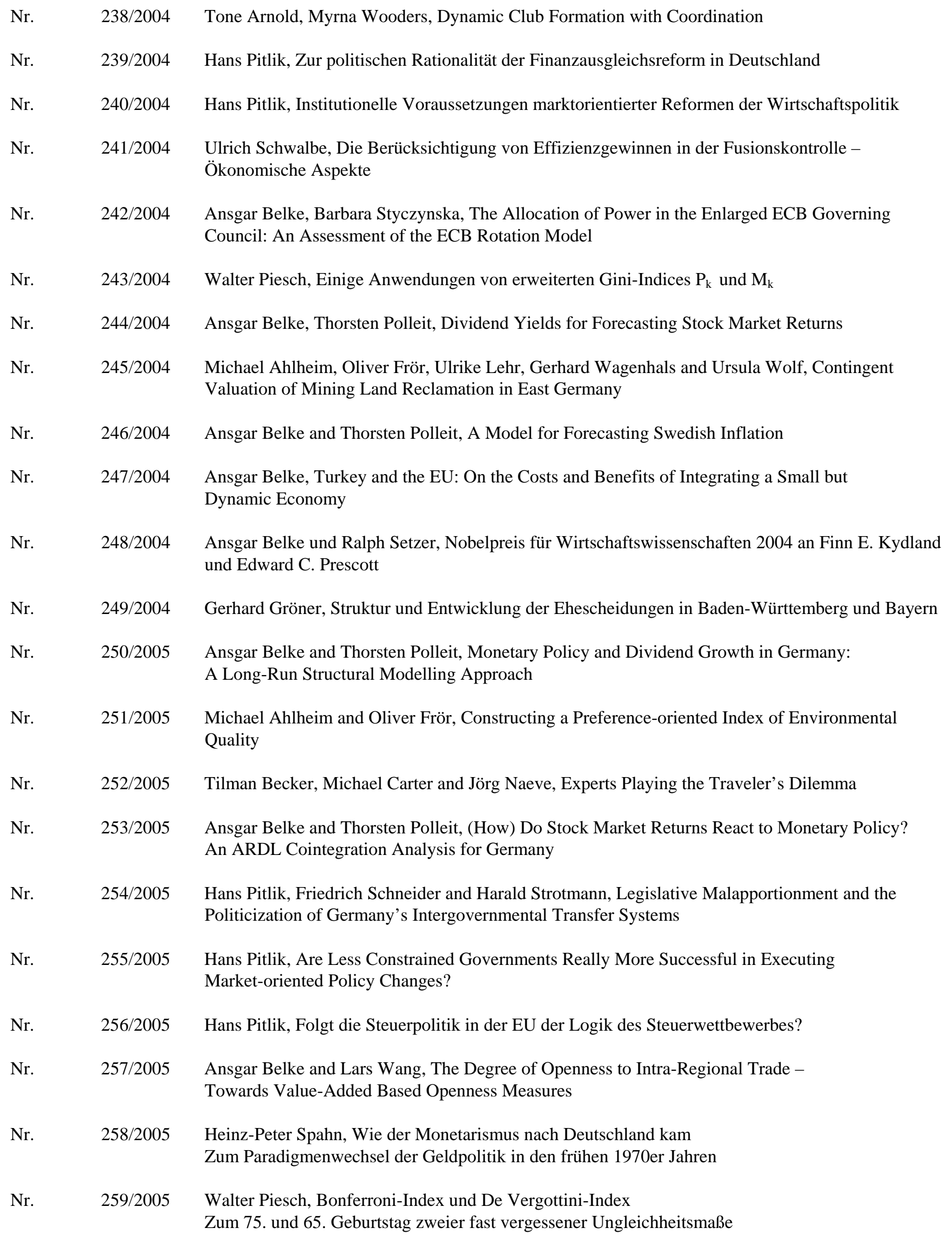


Nr. 260/2005 Ansgar Belke and Marcel Wiedmann, Boom or Bubble in the US Real Estate Market?

Nr. 261/2005 Ansgar Belke und Andreas Schaal, Chance Osteuropa-Herausforderung für die Finanzdienstleistung

Nr. 262/2005 Ansgar Belke and Lars Wang, The Costs and Benefits of Monetary Integration Reconsidered: How to Measure Economic Openness

Nr. 263/2005 Ansgar Belke, Bernhard Herz and Lukas Vogel, Structural Reforms and the Exchange Rate Regime A Panel Analysis for the World versus OECD Countries

Nr. 264/2005 Ansgar Belke, Frank Baumgärtner, Friedrich Schneider and Ralph Setzer, The Different Extent of Privatisation Proceeds in EU Countries: A Preliminary Explanation Using a Public Choice Approach

Nr. 265/2005 Ralph Setzer, The Political Economy of Fixed Exchange Rates: A Survival Analysis

Nr. 266/2005 Ansgar Belke and Daniel Gros, Is a Unified Macroeconomic Policy Necessarily Better for a Common Currency Area?

Nr. 267/2005 Michael Ahlheim, Isabell Benignus und Ulrike Lehr, Glück und StaatEinige ordnungspolitische Aspekte des Glückspiels

Nr. 268/2005 Ansgar Belke, Wim Kösters, Martin Leschke and Thorsten Polleit, Back to the rules

Nr. 269/2006 Ansgar Belke and Thorsten Polleit, How the ECB and the US Fed Set Interest Rates

Nr. 270/2006 Ansgar Belke and Thorsten Polleit, Money and Swedish Inflation Reconsidered

Nr. 271/2006 Ansgar Belke and Daniel Gros, Instability of the Eurozone? On Monetary Policy, House Price and Structural Reforms

Nr. 272/2006 Daniel Strobach, Competition between airports with an application to the state of Baden-Württemberg

Nr. 273/2006 Gerhard Wagenhals und Jürgen Buck, Auswirkungen von Steueränderungen im Bereich Entfernungspauschale und Werbungskosten: Ein Mikrosimulationsmodell

Nr. 274/2006 Julia Spies and Helena Marques, Trade Effects of the Europe Agreements

Nr. 275/2006 Christoph Knoppik and Thomas Beissinger, Downward Nominal Wage Rigidity in Europe: An Analysis of European Micro Data from the ECHP 1994-2001 